\title{
Uso de los pronombres átonos en el español en contacto con otomí
}

\author{
Uso dos Pronomes átonos no espanhol \\ em contato com o otomí
}

Edith Hernandez Mendez ${ }^{2}$

https://orcid.org/0000-0002-3864-6259

DOI: $10.26512 /$ rbla.v12i1.29808

Recebido em março/2020 e aceito em junho/2020

\section{Resumen}

Este estudio tuvo como objetivos determinar las condiciones internas y externas que motivan la variación y posible cambio en el sistema pronominal átono de acusativo en el español en contacto con otomí, en la comunidad de Santiago Mexquititlán (México), así como analizar la función del contacto en estos procesos. Para ello, analizamos un corpus con datos de 38 informantes. Los resultados muestran que el sistema pronominal átono de tercera persona de acusativo de esta comunidad de habla es muy similar al sistema etimológico, pues solo se registró un $16 \%$ de formas pronominales innovadoras; los objetos nulos y casos de leísmo fueron escasos. No obstante, mostramos un subsistema que evidencia una tendencia similar a la que constatamos en otras variedades de español en situación de contacto lingüístico intenso: las formas pronominales átonas de acusativo tienden a no especificar los rasgos de género y número. El contacto lingüístico desempeña una función fundamental en la variación y cambios aquí analizados, ya que no solo actúa como un acelerador del cambio, que posibilita la reorganización y recategorización del sistema pronominal átono de tercera persona, sino también como un factor que desencadena el cambio lingüístico.

Palabras clave: Pronombres átonos. Acusativo. Contacto lingüístico. Español. Otomí.

\begin{abstract}
This study aims at determining the internal and external constraints that motivate the variation and possible language change in the unstressed pronoun system of accusative in the variety of Spanish in contact with otomí, in Santiago Mexquititlán (Mexico), as well as analyzing the role of language contact in these processes. For this, we analyzed a corpus collected from 38 informants. We found that the the unstressed pronoun system of
\end{abstract}

1 Este trabajo forma parte del proyecto "El español en contacto con otras lenguas II:variación y cambio lingüístico" (Ministerio de Economía y Competitividad/Fondo Europeo de Desarrollo Regional, ref. FFI2015-67034-P, MINECO/FEDER). Agradezco a A.C.M. sus valiosos comentarios y al revisor que hizo observaciones a la primera versión.

2 Profesora-investigadora en la Universidad de Quintana Roo, Campus Chetumal, México. 
accusative in this speech community is remarkably similar to the etymological system, as only $16 \%$ innovative pronominal uses were registered; null objects and leísmo occurrences were scant. Nonetheless, we showed a subsystem which evidences a trend like the one documented in other varieties of Spanish in intense language contact: the unstressed pronouns of accusative tend to not specify the features of gender and number. Language contact plays a central role in the variation and change here analyzed, as this does not only accelerate the change, which makes possible the reorganization and recategorization of the unstressed pronominal system of third person, but this also triggers the language change.

Keywords: Unstressed pronouns. Accusative. Language contact. Spanish. Otomí.

\section{Introducción}

Desde hace unas décadas, el papel del contacto lingüístico en los estudios de cambio lingüístico ha sido de interés tanto para sociolingüistas, lingüistas históricos y los experimentales. Sin embargo, los fenómenos son multicausales y tan complejos, con una interacción de variables internas y externas, que es difícil, como bien señala Thomason (2010), hacer predicciones determinantes de dichos cambios. No obstante, analizar la variación y los procesos de cambio en situaciones de contacto es un objetivo alcanzable y recomendable, sobre todo en contextos poco explorados.

En los estudios de contacto de las variedades del español con lenguas amerindias, uno de los fenómenos que ha llamado la atención de diversos investigadores es el sistema pronominal átono, específicamente el de los pronombres de tercera persona con función de objeto directo. En estos estudios de diversas variedades de español en situación de contacto lingüístico intenso, se evidencia una tendencia de las formas pronominales átonas de acusativo a no especificar los rasgos de género y número, como se ilustra en los siguientes ejemplos:

\section{1). Allá mi difunta mamá lo llevan a hacer... comida allá.}

2). Dos banquillos agarro así...lo pongo así. Me paro a moler. (Español en contacto con maya. Hernández y Palacios 2015).

3).... él se fue allá donde le dijo que está el dinero; ah! que nomás le dijo que pusiera un santo y él fue allá y lo encontró el dinero, una caja grande lleno de dinero, se lo llevó (Español en contacto con tepehuano del sureste. Torres Sánchez 2015).

Se trata así de sistemas simplificados, reorganizados, o recategorizados, como se reporta en estudios previos: Flores Farfán (1999), sobre el español en contacto con Náhuatl; García Tesoro (2010), con el Tzutujil; Calvo (199697), Godenzzi (1986), Granda (2001), Klee (1990), Klee y Caravedo (2005), Martínez (2000, 2006), Moya (2006), Palacios (2006), Paredes y Valdez (2008) 
o Pfänder (2009) sobre el español de quechua-hablantes en el área andina; Martínez (2001), Olate, Wittig y Hasler (2014), sobre el habla de los mapuche; Granda (1996), Guillán (2012), Martínez (1996, 2000) y Palacios (1998, 2000), con respecto al español en contacto con el guaraní.

Sorprendentemente, en México, un país cultural y lingüísticamente diverso en el que coexiste el español con 68 lenguas originarias (INALI 2015), los estudios de contacto no son tan prolíficos. La bibliografía reciente en México sobre el sistema pronominal átono de tercera persona, específicamente, es poca en realidad. Del español en contacto con maya, se cuenta con el de Hernández y Palacios (2015); del habla de los bilingües tepehuanos del sureste, con los de Torres Sánchez (2015 y 2018); y de español en contacto con otomí, con el de Lizárraga (2014) y el de Avelino (2017). Estos estudios, si bien incipientes, resultan relevantes y pertinentes en el campo del contacto lingüístico, dada su sistematicidad, las diferencias tipológicas de las lenguas estudiadas en relación con el español, y el uso de datos vigentes y auténticos recogidos en las comunidades bilingües. Además, cada comunidad de habla es distinta en términos del grado del contacto: Hernández y Palacios (2015) trabajan con una comunidad con un bilingüismo histórico y un contacto intenso; Lizárraga (2014) y Avelino (2017), con una con contacto mínimo; de hecho, en situación de desplazamiento de la lengua amerindia; y Torres Sánchez $(2015,2017)$, en una comunidad con un bilingüismo incipiente.

Los resultados de estas investigaciones coinciden con los estudios previos realizados en otros contextos bilingües en América: reorganización del sistema pronominal con neutralización del género $\mathrm{y}$, en menor medida, del número, con un efecto de las variables instrucción y grado de bilingüismo (excepto en el estudio de Lizárraga, quien no incluyó estas variables). Es decir, se ha encontrado que, a menor nivel de instrucción, más neutralizaciones; y que son los bilingües consecutivos e incipientes en español los que producen más las variables innovadoras. Avelino (2017) también encuentra que son los adultos mayores los que más producen las neutralizaciones.

El otomí es una de las lenguas originarias en México que ha sido objeto de estudio frecuente. No son pocos los estudios previos sobre el español en contacto con esta lengua, además del de Avelino (2017), referido anteriormente, Lastra (1987); Hekking (2001); Guerrero Galván (2006, 2009); Guerrero Galván y San Giacomo (2014); y Lizárraga (2014), los cuales han evidenciado también variación en el sistema pronominal átono de tercera persona en el español de bilingües con una tendencia a la simplificación de las formas pronominales.

Si bien hay bibliografía sobre el fenómeno del sistema pronominal átono en el español de otomíes, es necesario, para los estudios de contacto, contar con comunidades de habla con diferentes grados de bilingüismo, con un tipo de contacto diferente y con actitudes de los hablantes diferentes, pues estos son 
factores que impactan la variación y el cambio lingüístico. De ahí la necesidad de realizar investigaciones con datos reales e integrando estas variables. Por tanto, en este estudio, nos planteamos determinar las condiciones internas y externas que motivan la variación y posible cambio en el sistema pronominal átono en el español en contacto con otomí en la comunidad de Santiago Mexquititlán en México. Nos interesa también analizar la función del contacto en estos procesos. Para ello, analizamos un corpus con datos de 38 informantes a partir de variables externas (sexo, edad, nivel de instrucción, escala de bilingüismo) y variables internas (semánticas).

\section{Perspectiva teórica}

En esta sección, presentamos los conceptos fundamentales en estudios de contacto, así como algunas perspectivas teóricas sobre los procesos de variación y cambio, en general, y específicamente del sistema pronominal átono del español en situación de contacto.

\subsection{Variación del sistema pronominal átono en español}

El sistema etimológico o distinguidor consiste en el "empleo de las formas herederas del acusativo latino lo, la, lo para el objeto directo y de la forma derivada del dativo le, para el objeto indirecto u otros usos compartidos con el dativo latino". (Fernández Ordóñez 1999: 1319). Existen, además, otras posibilidades de variación: leísmo, loísmo y laísmo, las cuales se han documentado desde la Edad Media (Flores Cervantes 2006). En México, contexto de nuestro interés en el presente estudio, el sistema etimológico es empleado principalmente en el español estándar.

En relación con la variación del sistema pronominal átono de tercera persona por contacto lingüístico, Fernández Ordoñez (1999:1341) observa tres tendencias: 1) omisión del pronombre átono en contextos en que este es obligatorio; 2) redundancia pronominal de los objetos directos (propia en los indirectos); 3) simplificación del sistema en una forma: le, o en dos: le y lo.

Tras hacer un análisis de diferentes sistemas pronominales en las áreas de contacto hispanoamericanas, Palacios (2005: 78) encuentra sistemas bicasuales con neutralización del rasgo de género (y número en menor medida): lo para acusativo y le para dativo en español de bilingües de Perú y Guatemala; y sistemas pronominales monocasuales con neutralización del rasgo de caso: ya sea lo o le en bilingües de Ecuador y Paraguay. No obstante, advierte la misma Palacios que, junto con este sistema simplificado, coexisten otros paradigmas, como el etimológico o distinguidor. Esta variación está relacionada con el grado de bilingüismo, la clase social y el nivel de instrucción.

Palacios (2005) plantea la hipótesis de que "los fenómenos de contacto suponen procesos generales de cambio, que tienen lugar de la misma manera 
y actúan en la misma dirección porque son procesos de cambio generales en los que actúan mecanismos similares, que dan lugar a efectos o consecuencias lingüísticas similares también." (p. 71). Para que esto ocurra, se requieren de algunas condiciones: a) una situación de contacto intensa; b) lenguas con características estructurales similares (no gramaticalizan el género ni el número y no tienen una distinción casual que se corresponda con el dativo y acusativo del español); el español muestra variación en su sistema pronominal, lo cual lo hace inestable. (Palacios 2005, 72).

Estos procesos de cambios implican la neutralización de al menos uno de los rasgos de caso, género y número, lo que conlleva a la simplificación del paradigma pronominal en regiones de contacto lingüístico. De esta manera, arguye Palacios, el subsistema pronominal andino peruano y el de contacto con maya tzutujil en Guatemala, muestran una tendencia conservadora al neutralizar género y número, pero mantienen la distinción de caso, de tal manera que estas formas pronominales cumplen más bien una función de marcas de objeto; un subsistema bicasual con marca para objeto directo (lo) y para objeto indirecto (le). Trabajos recientes, como el de Hernandez y Palacios (2015), Torres (2018) y Avelino (2017) evidencian resultados un tanto similares en variedades del español mexicano en contacto con el maya yucateco, el tepehuano y el otomí, respectivamente.

Por otra parte, el subsistema pronominal ecuatoriano y paraguayo son innovadores en tanto que muestran una tendencia hacia la neutralización del caso, el género y, en menor, medida, del número. Así, su sistema simplificado consta de le tanto para objeto directo como para objeto indirecto. De esta manera, la misma Palacios propone que el proceso general de cambio observado se basa en una jerarquización de rasgos semánticos que afectan la selección pronominal (caso, género, número) y que la neutralización de uno o varios no es aleatoria. En una primera etapa, se neutraliza el rasgo de género (y en menos medida el número); y en una segunda, se neutraliza el caso.

Esta jerarquización semántica de rasgos, añade la autora, está avalada también por estudios de adquisición del español como lengua materna (L1) o como segunda lengua (L2) (Véanse los estudios de Aguado (2000), Hernandez Pina (1990), Pueyo (1992), Klee (1989), Calvo (1996) y Collantine (1987) referenciados por Palacios), los cuales evidencian la adquisición en primer lugar de la distinción de caso, seguida de la de número y género, en la mayoría de los casos (aunque el número puede ser el último en algunos).

Hernández (2017) invoca también estos casos de adquisición en contextos monolingües y bilingües para explicar el proceso de cambio en situación de contacto. Con referencia a estudios previos (Domínguez 2003 con niños monolingües; Ezeizabarrena $(1996,1997)$ con niños bilingües vasco y español; De la Mora (2004), con niños con impedimento del habla), la autora resume que la adquisición de los clíticos en español puede consistir en diferentes etapas 
de desarrollo: primero se adquieren los clíticos de primera y segunda persona y después los de tercera persona. Además, en relación con esto últimos, se observa una primera fase con el uso de lo como pronombre exclusivo para codificar objetos. Montrul $(2004,201)$ apunta que, si el clítico lo es la forma por defecto en estas etapas de adquisición, los clíticos pueden ser meros marcadores de concordancia libres de propiedades referenciales.

Ante esta convergencia en la adquisición del español en niños y adultos, Hernández (2017) propone la existencia de una primera etapa en la cual, ante tanto input y material lingüístico (los cuales implican una fuerte actividad mental y diferentes procesos cognitivos para su procesamiento y consiguiente producción), es natural el uso de estrategias que satisfagan la necesidad comunicativa inmediata. Estas estrategias implican, precisamente, la aplicación de los universales de Greenberg (1963) en cuanto a las jerarquías semánticas: caso>género $>$ número, y de la teoría de la marcación. Así, van a preferir la distinción de caso, y las formas no marcadas: masculinas para género; y singular para número en una fase inicial de la adquisición.

En una sucesiva etapa, se evidencian tendencias divergentes entre los dos grupos (niños y adultos) condicionadas por factores extralingüísticos, principalmente, como son la frecuencia de input (podemos agregar cantidad y calidad), la frecuencia de uso de las formas normativas, la evidencia positiva y la propia madurez del niño. En un contexto monolingüe de español, se favorecen estos factores de manera tal que los niños adquieren la especificación de los rasgos de género y número, y los integran a su interlengua. No obstante, en el caso de los bilingües (niños y adultos) en contextos de intenso contacto, las condiciones difieren, pues hay una exposición a dos lenguas en distinto grado, por lo que la calidad, cantidad y frecuencia del input de la lengua española puede ser menor. Además, la frecuencia de uso de las formas normativas del español y la evidencia positiva pueden diferir significativamente. (Hernández 2017, 179). Estas circunstancias conllevan al mantenimiento de la distinción del caso (que se dio en la primera etapa), y a casos de variación y cambio en relación con los rasgos de género y número de las formas pronominales, que remiten a una restructuración parcial o total. Por razones de espacio, no tratamos aquí la elisión de pronombres o construcciones dobladas.

Otros factores que determinan estas divergencias entre los grupos (contextos sin contacto vs. contextos en contacto) son el nivel de instrucción y la presión social.

Además, muchos de estos hablantes bilingües tienen un nivel educativo bajo (a veces solo primaria) y la evidencia positiva que reciben o las presiones sociales o lingüísticas normativas a las que se someten son pocas (en la escuela o en sus lugares de trabajo). Estos hablantes bilingües se comunican efectivamente con la comunidad monolingüe 
con este sistema pronominal reorganizado y recategorizado y no tienen mucha presión para dejar de usarlo (con la excepción de aquellos que continúan estudios superiores o se insertan en un mercado laboral que los presiona lingüísticamente). (Hernández 2017, 179).

Bullock y Toribio (2006), citando a Schmidt (1985) y a Dorian (1994), señalan que en comunidades bilingües donde no hay presiones lingüísticas normativas, es patente una mayor variación.

\subsection{Cambios inducidos por contacto}

Thomason $(2008,47)$ define el cambio inducido por contacto como "Cualquier cambio lingüístico que tenga menos probabilidades de ocurrir fuera de una situación de contacto especifica se debe al contacto" (Mi traducción) ${ }^{3}$. Y subraya el hecho de que se trata de una fuente solamente, pues los cambios son multicausales.

Por su parte, Palacios $(2011,25)$ propone que el cambio indirecto inducido por contacto consiste en cambios multicausales compatibles con las tendencias internas del sistema. Se trata de un cambio motivado tanto interna (evolución interna de la lengua) como externamente (por el contacto de otras lenguas). El cambio lingüístico se produce a partir de una variación ya existente y, por tanto, no hay importación de material de otra lengua. El contacto funciona como un acelerador del cambio. Al referirse al contacto del español con las lenguas amerindias, Palacios Alcaine $(2017,8)$ enfatiza: "Concebimos así el cambio lingüístico inducido por contacto como procesos dinámicos que implican en muchos casos cambios conceptuales, cognitivos, culturales o pragmáticos; cambios complejos, sistemáticos o individuales, en los que subyace una explicación general".

En relación con el sistema pronominal átono del español de zonas de contacto, en particular, Palacios $(2017,9)$ declara que se trata de sistemas aparentemente simplificados cuyos pronombres pierden las distinciones funcionales de género y/o de número (relevantes en el sistema pronominal etimológico), y se convierten en marcas de concordancia de objeto. Es decir, que nos encontramos con un proceso de gramaticalización inducido por contacto; un cambio motivado interna y externamente (por el contacto). Destaca, además, que este cambio no sigue los patrones de evolución universales sugeridos por los universales del lenguaje y de las jerarquías interlingüísticas propuestas; es decir, que va en contra de las teorías tipológicas-funcionales, y esto se debe al contacto intenso con las lenguas que, si bien pertenecen a familias lingüísticas distintas, comparten la característica de no tener un sistema pronominal átono como el del español y no tienen marcas gramaticales de género.

3 "Contact is a source of linguistic change if it is less likely that a particular change would have happened outside a specific contact situation". 
No obstante, esto no es así de simple; aunque hay evidencia de que diferentes comunidades de contacto llegan a soluciones similares debido a la congruencia estructural de las lenguas, también se ha documentado la construcción de soluciones diferentes en comunidades bilingües donde se hablan las mismas lenguas en relación con un mismo fenómeno; esto indica la complejidad de las situaciones de contacto. (Palacios Alcaine 2017, 9-10). Así lo resume la estudiosa del contacto del español con lenguas originarias en América:

Defendemos, por tanto, que en el contacto de lenguas lo relevante son las similitudes estructurales $y / o$ las equivalencias funcionales que los hablantes perciben entre las lenguas implicadas, y que son estas las que realmente condicionan los cambios inducidos por contacto, creando soluciones emergentes altamente productivas que resultan congruentes con las lenguas implicadas. Desde esta perspectiva, el estudio de las situaciones de contacto lingüístico permite perfilar mejor las jerarquías y escalas universales que las regulan. (Palacios Alcaine 2017, 12-13).

\subsubsection{Factores lingüísticos y sociales como predictores de cambios inducidos por contacto}

Thomason (2008: 49) advierte que, para explicar cabalmente un cambio en una situación de contacto, se deben considerar tanto factores internos potenciales como externos, pues la causalidad múltiple en este tipo de situaciones es común. Añade que podemos hablar de factores necesarios, pero no suficientes. Así, Thomason (2010, 36-37), aduce a factores sociales y lingüísticos que pueden condicionar los cambios inducidos por contacto. Dentro de los primeros, describe tres como relevantes: la presencia vs. la ausencia de un aprendizaje imperfecto, la intensidad del contacto y las actitudes de los hablantes.

La presencia vs. la ausencia de un aprendizaje imperfecto es explicada en función del nivel de bilingüismo de los hablantes de la comunidad. Si los hablantes tienen un alto nivel de bilingüismo, se observan transferencias léxicas de vocabulario no básico en primer lugar; sin embargo, después de un prolongado contacto, pueden darse transferencias estructurales y de vocabulario básico. En contraste, si los hablantes muestran un aprendizaje imperfecto de la lengua meta, lo que se observa, en primera instancia, son transferencias estructurales (Thomason 2010, 36).

En relación con la intensidad del contacto, argumenta que cuanto mayor sea el periodo de contacto y el nivel de bilingüismo en la comunidad en cuestión, mayor probabilidad hay de transferencia de rasgos estructurales y léxicos. El número de hablantes de la lengua fuente y la lengua receptora, el grado de acceso a la lengua meta y el tiempo del contacto afectan los cambios en las 
zonas de contacto. La intensidad del contacto tiene un papel relevante tanto en la emergencia de las variables innovadoras como en la difusión de los cambios inducidos por contacto (Thomason 2010, 39).

Finalmente, siguiendo a la misma autora, las actitudes de los hablantes desempeñan una función importante en los cambios inducidos por contacto y en los motivados internamente. Un claro ejemplo del papel de las actitudes como causa de cambio se observa en los cambios deliberados o intencionados, que pueden transparentarse en cuestiones de planeación lingüística, o en situaciones donde una comunidad desea distinguir su lengua o dialecto del de sus vecinos (Thomason 2010, 38).

En cuanto a los predictores lingüísticos, tanto de cambios inducidos por contacto como de cambios motivados internamente, la investigadora distingue el marcado universal (learnability), y el grado de integración en el sistema; y solo para cambios inducidos por contacto, agrega la distancia tipológica. Esta última es una medida de las diferencias estructurales entre dos lenguas. Así, el grado de distancia tipológica entre los subsistemas específicos de las lenguas en situación de contacto ayuda a predecir los tipos de interferencia que pueden ocurrir en ciertas situaciones de contacto según su grado de intensidad. (Thomason 2010, 40).

El marcado universal se relaciona con la facilidad de aprendizaje (learnability), ya que se cree que las formas marcadas son más difíciles de aprender que las no marcadas. Thomason (2010) declara que "learnability" o la facilidad de aprendizaje de una lengua se relaciona con las presiones de los modelos o de los contrastes estructurales, los cuales hacen que ciertas formas o estructuras sintácticas sean relativamente más difíciles de aprender que otras.

El grado de integración en el sistema hace referencia a la relación estrecha o abierta entre los diferentes subsistemas lingüísticos. Los cambios inducidos por contacto son más comunes en subsistemas integrados de manera abierta que en aquellos integrados de forma estrecha en los que las formas se interconectan en conjuntos, que la vez se organizan en paradigmas (como es el caso de la morfología flexiva). La transferencia de formas flexivas solo ocurre en situaciones de un contacto intenso. (Thomason 2010, 45).

\subsubsection{El concepto de transparencia en el cambio lingüístico}

Un concepto usado por Langacker (1977) para explicar el cambio lingüístico es el de transparencia. También se ha recurrido a este en la adquisición de lenguas (Slobin 1977) y en el área de las lenguas criollas (Seuren y Wekker 1986). Leufkens (2013) y Hengeveld y Leufkens (2018) retoman el concepto de transparencia, y la definen, a partir de Hengeveld (2011), como la relación unívoca entre forma y significado en la que la primera puede ser un morfema, una palabra o una unidad lingüística más grande. La diferencia con el concepto 
de transparencia semántica de Seuren y Wekker $(1986,64)$ es que, para estos, la transparencia semántica implica, además de esta misma relación unívoca, un procesamiento mínimo y una cantidad mínima de reglas particulares a la lengua. Leufkens solo se refiere a la primera parte (la relación entre forma y significado) y distingue la noción de transparencia de los términos de simplicidad, facilidad de adquisición y regularidad con los que suele intercambiarse en la bibliografía.

En breve, la simplicidad hace referencia a la cantidad de material lingüístico y uso de estructuras superficiales (reducido inventario fonológico; pocas reglas morfológicas y fonológicas; grado reducido de estructuras profundas; y regularidad paradigmática). La facilidad de adquisición se relaciona con un diferencial reducido entre la L1 y la L2; con una saliencia perceptual alta de un rasgo lingüístico; con la alta frecuencia de un rasgo; con la regularidad y con la transparencia. Finalmente, la regularidad paradigmática se refiere a la posibilidad de predecir los paradigmas en la lengua; a la conformación consistente de un paradigma por parte de sus miembros. (Leufkens 2013, 329-30).

Leufkens (2013) y Hengeveld y Leufkens (2018) hipotetizan que el contacto lingüístico propicia más transparencia en las lenguas implicadas. Así, en situaciones de contacto, se espera una mayor frecuencia de formas transparentes que de opacas, dado el alto grado de inteligibilidad de las primeras $\mathrm{y}$, consecuentemente, se favorecen cambios lingüísticos dirigidos hacia una transparencia más rica. En situaciones de contacto intenso donde hay una necesidad inmediata de comunicarse entre los hablantes de ambas comunidades, y en lenguas tipológicamente diferentes, este efecto debería ser mayor. Para medir la transparencia, los autores proponen analizar tres categorías de opacidad: redundancia, desintegración de dominios, y formas basadas en la forma (categorías vacías semántica y pragmáticamente). En redundancia, encontramos el número y en la de formas basadas en la forma, las concordancias y el género gramatical, entre otros.

Los autores usan el concepto de transparencia para discutir las lenguas criollas en particular, aunque indican que esta se da en situaciones de contacto, en general. Si hablamos de lenguas en contacto, inferimos, entonces, que los fenómenos lingüísticos producto del contacto mostrarán tendencias hacia la transparencia. De esta manera, es claro que en el caso de los pronombres de objeto directo en español en contacto con lenguas indígenas u otras lenguas, se espera que haya variación o cambio encaminados a la reducción de las formas opacas (género, número y caso).

\subsection{El sistema pronominal de objeto directo en otomí}

En relación con los pronombres átonos, en la siguiente tabla, se muestran los sufijos de objeto y de dativo en otomí de San Ildefonso Tultepec, documentados por Palancar (2009): 
Cuadro 23. Sufijos de Objeto y de Dativo. (Fuente: Palancar 2009, 227)

\begin{tabular}{|c|c|c|}
\hline & OBJ & DAT \\
\hline $1^{\mathrm{a}} \cdot$ & \multicolumn{2}{|c|}{$-\mathrm{g} / \mathrm{-k}$} \\
\hline $2^{\mathrm{a}} \cdot$ & \multicolumn{2}{|c|}{$-{ }^{-}$} \\
\hline $3^{\mathrm{a}} \cdot$ & $-\varnothing$ & $-\mathrm{p}(-\mathrm{b} / \mathrm{w})$ \\
\hline
\end{tabular}

Hekking y Andrés de Jesús $(1987,86)$ documentan los siguientes sufijos para el complemento directo:

\begin{tabular}{|l|l|}
\hline \multicolumn{2}{|l|}{ Sufijos complemento directo } \\
\hline -gi & (me) \\
\hline -i & (te) \\
\hline -na, un, ä & $($ lo, la $)$ \\
\hline -g(ö) & nos \\
\hline -a & (los, a uds). \\
\hline -ya, -yu, -u & (los, las). \\
\hline
\end{tabular}

Si los hablantes de la comunidad de habla del presente estudio tuvieran un sistema de complemento directo como el que documenta Palancar (2009), se esperarían omisiones de objeto directo en la producción de los bilingües; pero si tuvieran el paradigma propuesto por Hekking y Andrés de Jesús (1987), entonces se esperarían usos más cercanos al sistema etimológico o distinguidor del español mexicano estándar.

\section{La comunidad de habla}

Según el Instituto Nacional de Lenguas Indígenas INALI (2015) hay 68 lenguas ) en México. El otomí pertenece a la familia otopame del tronco oto-mangue, la cual integra 18 lenguas (amuzgo, chatino, chichimeco jonaz, chinanteco, chocholteco, cuicateco, ixcateco, matlatzinca, mazahua, mazateco, mixteco, otomí, pame, popoloca, tlahuica, tlapaneco, triqui y zapoteco). La población de hablantes de otomí es de 307,928 (148,707 hombres y 159,221 mujeres).

La lengua otomí se habla principalmente en poblaciones del altiplano central de la República Mexicana: Querétaro, Estado de México, Guanajuato, Hidalgo, Veracruz, Puebla, Tlaxcala y una pequeña porción en Michoacán. También, en la actualidad, hay inmigrantes otomíes en otros estados del territorio mexicano. En el mapa siguiente se observa la distribución geográfica: 
Distribución geográfica de poblaciones otomíes (Vargas García 2014: 47).

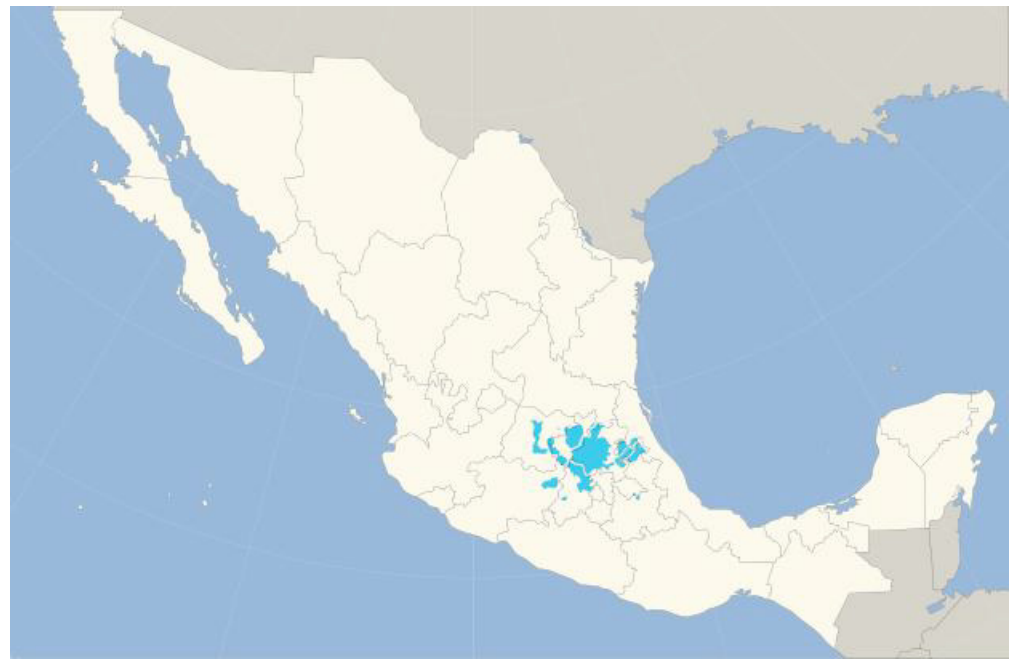

Santiago Mexquititlán, la comunidad de habla de este estudio, está ubicada a unos 21 kilómetros de la cabecera municipal (Amealco de Buenfil). Tavarez (2019) describe la comunidad así:

Santiago Mexquititlán es un pueblo indígena formado por "barrios" con sus raíces, idioma y vestimenta. Al paso del tiempo fueron mezclados con la religión católica para dar vida a una nueva cultura llena de color, simbolismos y sincretismo que da identidad a la comunidad.

El trabajo que las mujeres realizan es la elaboración de las muñecas, servilletas bordadas, fajas, quexquemett ${ }^{4}$; los hombres trabajan en el campo en la siembra del maíz o salen a buscar trabajo a otros estados o en busca del sueño americano. Los niños van a la escuela, ayudan en las labores de la casa y en la elaboración de las artesanías.

Los principales barrios de Santiago Mexquititlán donde se recolectaron los datos para este estudio son el primero y el quinto, con una población, según el INEGI (2010), de 1,646 y 1,794 habitantes, respectivamente. La población hablante de una lengua indígena con edad de 5 años o más en el municipio de Amealco de Buenfil es de 15,028. INEGI (2010). La situación lingüística del otomí en la actualidad parece ser de desplazamiento. Así lo señala Hekking (2002: 222):

\footnotetext{
4 Del náhuatl quechquēmitl. El quexquemetl es una prenda indígena de uso femenino que se sostiene del cuello por encima del huipil o la blusa, está bordado según el diseño de cada etnia y sirve para protegerse del frío, cubriendo la espalda y el pecho. (En https:// es.wiktionary.org/wiki/quexquemetl)
} 
En Santiago Mexquititlán [...] se observa un acelerado aumento del uso de la lengua española, una disminución del uso de la lengua indígena y el olvido de ciertas formas de la lengua materna por parte de los otomíes o ñãñho. Este proceso de desplazamiento lingüístico va acompañado de cambios lingüísticos tanto en el hñäñho como en el español.

Este desplazamiento parece ser una consecuencia de las actitudes negativas de la comunidad hacia la lengua otomí, entre otros factores. Así lo han documentado algunos investigadores:

Los factores que contribuyen a la pérdida del otomí y a la adquisición incompleta del español son múltiples, pero tanto la enseñanza deficiente en las escuelas como las actitudes negativas hacia la lengua otomí por parte de las clases dominantes y también de algunos otomíes se derivan todas en el fondo de la actitud negativa de la mayoría de los mestizos hacia la lengua y cultura indígena y la concomitante vergüenza que sienten muchos de ellos hacia su pasado. (Hekking 2002, 242).

Aquí está una de las mayores concentraciones de población indígena del estado, que hasta hace algún tiempo era víctima de discriminación por quienes hasta la fecha llaman "mestizos", siendo esta una de las razones principales por la cual durante muchos años fueron dejando de lado principalmente su idioma, vestimenta y cultura. (Tavarez 2019).

Aunque Tavarez (2019) es optimista, en la actualidad, en cuanto al mantenimiento de la lengua otomí y las actitudes positivas de sus hablantes, los otros autores evidencian lo contrario. Avelino (2017), por ejemplo, documenta sentimientos de marginación y de vergüenza por no saber español en los monolingües de otomí; también, reporta casos de discriminación y burla por este mismo hecho.

\section{Método}

Este es un estudio descriptivo basado en un corpus oral de habla espontánea. La muestra de 38 informantes en total está distribuida de la siguiente manera: Por sexo: 13 hombres y 25 mujeres; por edad, 22 informantes de 18 a 25 años; 13 de 26 a 50 años, y 3 de más de 51 años. Por nivel de instrucción: 16 tienen educación básica; 9, preparatoria; y 13 cuentan con estudios universitarios. Por grado de bilingüismo: 8 son bilingües funcionales o incipientes; 10 son bilingües consecutivos; 9 son bilingües simétricos y 11 son monolingües de español. Una limitación en este estudio fue, precisamente, contar con participantes en todos los grupos, pues fue principalmente difícil conseguir la colaboración de gente mayor. No obstante, en el análisis se considerarán las frecuencias relativas de cada informante en relación con el fenómeno de estudio. 
La escala de bilingüismo se determinó a partir de la propuesta de Palacios (2005), de un continuo que va desde el monolingüe en la lengua amerindia hasta el monolingüe en español pasando por el bilingüe incipiente (funcional en la L2), el consecutivo (adquisición de L1 y después de L2) y el simétrico (dominio de ambas lenguas). Esta escala de bilingüismo está basada en diversos criterios: la competencia del bilingüe en las dos lenguas, la edad y el contexto de adquisición, su nivel de instrucción y el ámbito (monolingüe o bilingüe) en el que se desempeña. Aunque no se aplicaron exámenes de competencia, sí se indagó con los informantes respecto a todos estos criterios a través de una entrevista. Se contó con un colaborador bilingüe, quien dialogaba brevemente con los bilingües en otomí en las entrevistas y ayudó así a determinar su competencia lingüística en dicha lengua. El resto de la entrevista y tarea lingüística fue en español y también estos instrumentos fueron útiles para determinar la competencia en español de los participantes.

El corpus se conformó a partir de entrevistas semidirigidas y una tarea lingüística. En la entrevista, se siguió un protocolo estilo laboviano para motivar el habla espontánea de los colaboradores. Dicha entrevista fue dirigida por una persona bilingüe (español-otomí) y una monolingüe de español. Después de la entrevista (que tuvo una duración de 40 a 60 minutos), se realizó una tarea lingüística en la que, mediante el uso de unas imágenes, se estimuló la producción de los pronombres átonos de tercera persona. En las imágenes se incluyeron referentes masculinos y femeninos, humanos y no humanos, animados e inanimados, singulares y plurales. Se les pedía a los informantes que describieran la escena en la que generalmente interactuaban algunos personajes. Se presentaron 35 imágenes en total, de las cuales 10 eran distractores. Los informantes podían describir la imagen tanto como quisieran. Sin embargo, en algunos casos, cuando no producían pronombres, se les hacían preguntas adicionales sobre las mismas imágenes para estimularlos. Es decir, se les cuestionaba sobre qué estaba pasando o iba a suceder; qué hacían las personas; por qué estaban ahí; preguntas todas relacionadas con la situación en las imágenes.

El corpus se constituyó de 1161 pronombres de objeto directo, obtenidos de la entrevista y de la tarea. Se eliminaron casos ambiguos en los que el referente no era claro; casos de expresiones o frases lexicalizadas y aquellos de se impersonal seguido de pronombre átono, dado que en México es habitual se le/les y no hay evidencia de variación.

Los datos se analizaron en relación con variables internas: género, número, animacidad, definitud, especificidad, continuidad y rasgo \pm humano del referente; así como animacidad y rasgo \pm humano del sujeto. Las variables externas fueron sexo, edad, nivel de instrucción y escala de bilingüismo/monolingüismo. No se incluye la variable estilo en el análisis porque en la tarea se logró un alto grado 
de espontaneidad en el habla de los informantes. Se usaron siete variantes de la variable lingüística (pronombre de objeto directo): la, lo, las, los, las, le, les y Ø.

Para determinar relaciones de dependencia de las variables, se utilizó el software estadístico SPSS (Statistical Package for the Social Sciences) versión 25. Se realizaron pruebas estadísticas no paramétricas de chi cuadrado y la V de Cramer para determinar el grado de asociación y la significancia de las variables en cuestión. También se realizaron análisis con cruces entre variables internas y externas. Los resultados se presentan en tablas de contingencia con porcentajes y frecuencias y los valores significativos correspondientes.

\section{Resultados y discusión}

Los objetivos de esta investigación fueron determinar las condiciones internas y externas que motivan la variación y posible cambio en el sistema pronominal átono en el español en contacto con otomí en la comunidad de Santiago Mexquititlán, así como analizar la función del contacto en estos procesos. Esta sección, por tanto, sigue este orden en la presentación de los hallazgos.

Empezamos así con las variantes de los usos pronominales de tercera persona encontradas en los 1161 datos. En la tabla 1, se muestra la distribución de uso de todas las variantes pronominales con función de objeto directo, así como de la omisión del pronombre.

Tabla 1. Variantes pronominales de $3^{\mathrm{a}}$. Persona función acusativa

\begin{tabular}{|c|c|c|c|c|c|c|c|c|c|c|c|}
\hline la & & lo & las & & los & & & & les & & sión \\
\hline $202 \quad 17.4 \%$ & 563 & $48.5 \%$ & $968.3 \%$ & 272 & $23.4 \%$ & 12 & $1 \%$ & 6 & $0.5 \%$ & 10 & $0.9 \%$ \\
\hline
\end{tabular}

\section{Abajo ilustramos estos usos pronominales:}

1) El agua pus sabemos que lo agarramos para bañarnos......(Informante 13, mujer, 26-50 años, nivel medio superior, bilingüe simétrica).

2) E: ¿Qué piensa usted que hará la mujer con las flores?

F: Eh... creo que las pondrá en un florero. ...(Informante 18, mujer, 18-25 años, universitaria, bilingüe consecutiva).

3) Terminas los dos lienzos, ahora los unes con una aguja de coser... (Informante 14, mujer, 26-50 años, nivel básico, bilingüe incipiente).

4) Parece que tienen ahí dinero en uno... no quiere que se dé cuenta el otro donde está, como que le está engañando. ...(Informante 38, mujer, 26-50, nivel básico, bilingüe consecutiva).

5) Has notado, no sé, alguna diferencia con algún otro otomí que hayas escuchado de otro lado, por ejemplo, de, de allá de Mialco ¿o no lo has escuchado? 
A: No. Yo... la mera verdad no he escuchado.

6) Los niños andaban jugando futbol y le rompieron su jarrón a su mamá. Su mamá no sé si les pegaría o las regañó, pero los niños están llorando. ... (Informante 14, mujer, 26-50, nivel básico, bilingüe incipiente).

De esta manera, el sistema favorecido por la muestra (38 informantes) de esta comunidad de habla es el etimológico o distinguidor; y son casi nulos los usos de leísmo ( $1.5 \%$ del total) y de la omisión pronominal $(0.9 \%)$. Este último resultado sobre la omisión no coincide con una de las tendencias generales que Fernández Ordoñez (1999) reporta en los sistemas pronominales en situación de contacto, ni con los resultados de estudios previos: Gómez Seibane (2012) y Camús y Seibane (2015) sobre la omisión en el español en contacto con vasco; Granda (1996) y Palacios (2015) del español con quichua en la zona andina (48.1\% de elisiones); Palacios (1998) sobre el español en contacto con guaraní; García Tesoro (2010) sobre el español con maya tzutujil; Torres (2018), en el español en situación de contacto con tepehuano (36.1\% de elisiones); Hernández y Palacios (2015) en el español con maya yucateco (12.5\% de objetos nulos).

No obstante, estos hallazgos sobre la omisión coinciden con los previos en contextos de contacto español-otomí: Lizárraga (2014) registra un 5\% de omisiones en la comunidad de Pueblo Nuevo, municipio de Acambay, Estado de México, y Avelino (2017) no analizó la omisión de pronombres de objeto directo en su estudio sobre el español en contacto con otomí, dado que declaró que esto ocurrió con poca frecuencia.

Esta casi ausente omisión pronominal no puede relacionarse con el sistema de complemento directo en la misma lengua otomí, ya que Palancar (2009) documenta un cero fonético para los pronombres de tercera persona en una variedad de otomí, aunque Hekking y Andrés de Jesús (1987) registran las formas -na, un, $\ddot{a}$ en otro dialecto. Sin embargo, como sabemos, la convergencia estructural no es un requisito para los cambios inducidos por contacto, pues hay otras presiones.

Palacios (2015) y García y Fernández (2015: 138) concuerdan en señalar que la elisión pronominal es característica de las lenguas que poseen concordancia de objeto, proceso de cambio que se presenta de alguna medida en las variedades del español en contacto con lenguas amerindias. Palacios (2015: 104) precisa que "la omisión es la última etapa del proceso de gramaticalización de las formas pronominales átonas de tercera persona que experimenta el español desde la Edad Media...". Dados los resultados de este estudio y de los previos del mismo contexto, el paradigma pronominal átono de esta variedad del español en contacto con otomí parece estar aún distante de esta última fase de gramaticalización. 
Analizaremos, enseguida, los usos de los pronombres la, lo, las los (sin leísmo ni omisiones dada su escasa ocurrencia) y su relación con las variables internas y externas. Veamos en la siguiente tabla su relación con el género del referente:

Tabla 2. Pronombres con referente género

\begin{tabular}{|c|c|c|c|c|c|c|}
\hline Género referente & la & lo & las & & los & n \\
\hline Masculino & $91.2 \%$ & $46965.2 \%$ & $7.09 \%$ & 234 & $32.5 \%$ & 719 \\
\hline Femenino & $19252 \%$ & $7018.9 \%$ & $86 \quad 23.3 \%$ & 22 & $5.9 \%$ & 369 \\
\hline $\mathrm{n}$ & 201 & 539 & 93 & 256 & & \\
\hline
\end{tabular}

Los resultados muestran usos muy cercanos al sistema etimológico, ya que si sumamos las frecuencias de los usos innovadores de todas estas variantes (108), solo conforman un 10\% del total de los datos. Nótese, no obstante, que, aunque es reducida la presencia de formas emergentes, lo y los se muestran como las variantes más frecuentes con usos innovadores al seleccionarse para entidades femeninas en un $24.8 \%$ del total de posibilidades. Veamos algunos ejemplos para ilustrar estos usos:

6) E: ¿Y cree usted que el niño, después que reclamen, entregue la muñeca? B: No ps si lo tiene que entregar. ...(Informante 21, hombre, 26-50 años, nivel básico, bilingüe consecutivo).

7) I: aquí veo a un muchacho que va caminando por un pasillo. Y unas muchachas levantando la mano.

E: ¿Y qué hace este muchacho?

I: Ps los ignoró. ...(Informante 21, hombre, 26-50 años, nivel básico, bilingüe consecutivo).

8) Pus que sí está bien, pero toda le... para mí, siento que le falta mucho para que lo terminen de arreglar, para que quede bonito (la iglesia). ...(Informante 30, mujer, 26-50 años, nivel medio superior, bilingüe simétrica).

9) lo que es costillita de res, ya sea que lo prepare con... un poco de que es cerveza y limón o/y naranja ...(Informante 31, hombre,18-25, nivel medio superior, bilingüe incipiente).

Veamos enseguida la relación de las variantes con el rasgo de número en la tabla 3. 
Tabla 3. Pronombres con referente número

\begin{tabular}{|c|c|c|c|c|c|c|c|c|c|}
\hline Número referente & & la & & lo & & las & & los & n \\
\hline Singular & 188 & $25.8 \%$ & 496 & $68.3 \%$ & 8 & $1.1 \%$ & 33 & $4.5 \%$ & 726 \\
\hline Plural & 12 & $3.3 \%$ & 42 & $11.6 \%$ & 85 & $23.4 \%$ & 223 & $61.6 \%$ & 362 \\
\hline $\mathrm{n}$ & 202 & & 563 & & 96 & & 272 & & \\
\hline \multicolumn{10}{|l|}{$\mathrm{N}=1088$} \\
\hline
\end{tabular}

La relación de los pronombres átonos de objeto directo con el número del referente es muy similar a la que se tiene con el rasgo de género, ya que las formas etimológicas se presentan en más del $90 \%$ de las ocurrencias. Son 95 los usos innovadores en relación con el número; es decir, un $8.7 \%$ de usos innovadores. Al igual que con el género, lo seguido de los son las variantes más recurrentes en estas formas emergentes: lo para referentes plurales $(11.6 \%) \mathrm{y}$ los con referentes singulares (4.5\%.) Abajo presentamos algunos ejemplos que evidencian los usos encontrados (tanto de uso estándar como de uso innovador):

10) ...frío las tortillas con un-un-un... no tan fritas sino simplemente nada más una cuanta...pasada, de ahí ya nada más las... las doblo y las hago como en taquitos...(Informante 1, mujer, 18-25 años, universitaria, monolingüe).

11) Bueno, esas, a mí me enseñaron a hacerlas con un resorte muy delgadito que es especial para hacerlo [pulceritas con chaquiras] ....(Informante 3, mujer, 18-25 años, medio superior, monolingüe).

12) Ya que los haiga buscado (los nopales)... Los empieza a pelar ... Los pica, bueno les quita las espinas. ...(Informante 13, mujer, 26-50 años, nivel medio superior, bilingüe simétrica).

Si bien todas las variantes evidencian algunas discordancias, parece haber una tendencia del uso innovador $l o$, con más frecuencia en la neutralización del género seguida de la de número, tal como se documenta en la mayoría de los estudios de contacto del español con alguna lengua amerindia. Veamos en la siguiente tabla la relación de estas dos variables (género y número) con las variantes estudiadas:

Tabla 4. Variantes con factores género y número referente

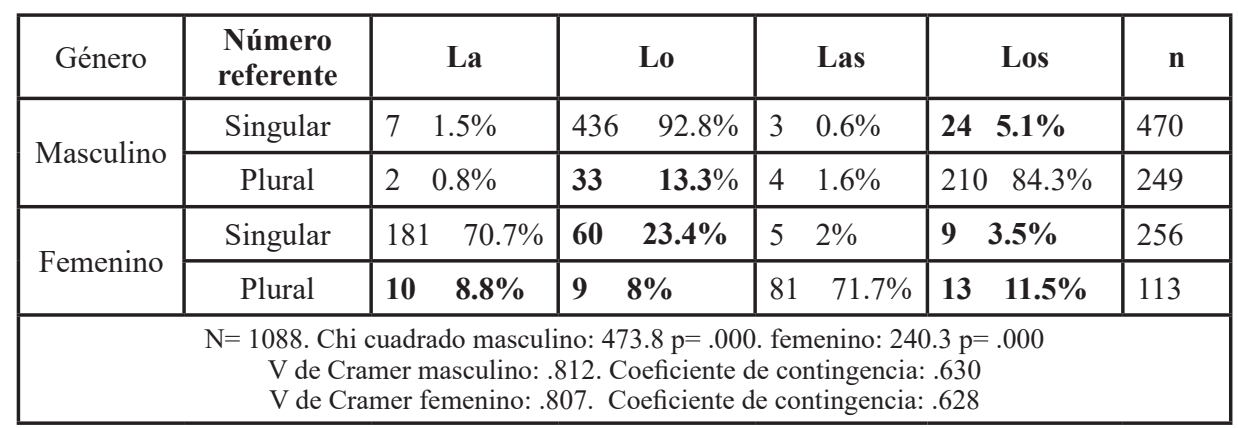


Las pruebas de chi cuadrado resultan significativas para los dos géneros, dado que la gran mayoría de los datos muestran relación del género y del número con cada variante; es decir, que se observa un patrón similar al sistema etimológico, en general, en el que hay concordancia gramatical con ambos rasgos. No obstante, con estos datos, se evidencian usos innovadores en 174 ocurrencias, lo que corresponde a un $16.4 \%$ del total de datos. Es decir, que se registraron $83.6 \%$ usos estándares. Queda claro con esta tabla que es el pronombre lo principalmente la variante innovadora más empleada por los informantes de esta comunidad de habla, seguida de los. Como arriba se mostró, hay ligeramente una mayor neutralización del rasgo de género que del de número.

Consecuentemente, en relación con los de estudios previos del español en contacto con otomí, este estudio (16.4\%) presenta un decremento en los porcentajes de formas emergentes: Lizárraga (2014) documenta un 39.6\% y Avelino (2017), un $21.8 \%$ de pronombres innovadores o alternativos. En comparación con estudios de contacto del español con otras lenguas en México, las cifras de las variantes innovadoras en este estudio son mucho menores: Torres (2018) registra un 38.8\% de producción de lo/los innovadores para el caso del español en contacto con tepehuano; y Hernández y Palacios, un 49\% de lo/los innovadores (con referentes femeninos) en su investigación del español en contacto con maya yucateco.

Dado que nuestro primer objetivo es determinar las variables externas e internas que condicionan esta variación y posible cambio, en la siguiente sección analizamos el sistema pronominal en relación con el género y las variables sociales: sexo, edad, nivel de instrucción y escala de bilingüismo.

\subsection{El sistema pronominal en función del género del referente}

En esta sección, presentamos un análisis del rasgo de género y su relación con las variables sociales. Para ello, agrupamos las variantes la/las y lo/los. Primeramente, veamos la relación con el factor sexo. En la tabla 5, se muestran las frecuencias y porcentajes.

Tabla 5. Variantes con factores sexo informantes y género referente

\begin{tabular}{|c|c|c|c|c|}
\hline Sexo & Género referente & La/las & Lo/los & $\mathbf{n}$ \\
\hline \multirow{2}{*}{ Hombres } & Masculino & $3 \quad 1.3 \%$ & $228 \quad 98.7 \%$ & 231 \\
\hline & Femenino & $103 \quad 83.7 \%$ & $20 \quad 16.3 \%$ & 123 \\
\hline \multirow{2}{*}{ Mujeres } & Masculino & $12 \quad \mathbf{2 . 5} \%$ & $472 \quad 97.5 \%$ & 484 \\
\hline & Femenino & $172 \quad 71.2 \%$ & $70 \quad 28.8 \%$ & 243 \\
\hline
\end{tabular}


La prueba de chi cuadrado resulta significativa $\mathrm{p}=.000$ en tanto que la variable sexo muestra dependencia con el rasgo de género, es decir, se evidencian usos de formas canónicas mayoritariamente en hombres y mujeres. No obstante, es importante observar la diferencia numérica en los valores de V de Cramer para hombres y mujeres, pues los hombres muestran más asociación con la variable de género. Atendiendo las frecuencias y los porcentajes, se observa que, efectivamente, las mujeres se comportan relativamente diferente a los hombres, pues son las que muestran mayores usos innovadores. Por consiguiente, no podemos concluir que el sexo condicione la variación, pero sí que parece haber una tendencia de las mujeres a favorecer las formas emergentes.

Aquí ilustramos estos usos:

13) Si es que es agua pus se lo van a tomar. ...(Informante 14, mujer, 26-50 años, nivel básico, bilingüe incipiente).

14) Veo a dos niños que están jugando fútbol y que rompieron una maceta en su casa y su mamá los está regañando. ...(Informante 16, hombre, 18-25 años, nivel básico, bilingüe simétrico).

15) E: ¿Qué piensa usted que va hacer la maestra con los niños que sí le ponen atención?

I: Pues las va a seguir dirigiendo para enseñarles más. ...(Informante 16, hombre, 18-25 años, nivel básico, bilingüe simétrico).

Otra variable social analizada fue la edad. En la tabla 6 se muestran los resultados de las variantes pronominales y su relación con la variable edad y género del referente. Por razones de espacio, ya no incluiremos más ejemplos cuyo propósito solamente es el mostrar los usos innovadores.

Tabla 6. Variantes con factores edad informantes y género referente

\begin{tabular}{|c|c|c|c|c|}
\hline Edad & Género referente & La/las & Lo/los & $\mathbf{n}$ \\
\hline \multirow{2}{*}{ Grupo A (18-25) } & Masculino & $6 \quad 1.5 \%$ & $98.5 \%$ & 394 \\
\hline & Femenino & $194 \quad 86.2 \%$ & $13.8 \%$ & 225 \\
\hline \multirow{2}{*}{ Grupo B (26-50) } & Masculino & $7 \quad 2.7 \%$ & $97.3 \%$ & 264 \\
\hline & Femenino & $74 \quad 64.9 \%$ & $40 \quad 35.1 \%$ & 114 \\
\hline \multirow{2}{*}{ Grupo C $(+50)$} & Masculino & $2 \quad 3.5 \%$ & 96.5 & 57 \\
\hline & Femenino & $8 \quad 29.6 \%$ & $70.4 \%$ & 27 \\
\hline
\end{tabular}

Si bien los grupos etarios que conformaron la muestra no están equilibrados (22 informantes de 18 a 25 años; 13 de 26 a 50 años, y 3 de más de 51 años), y esto representa una limitación metodológica para obtener datos más confiables, la prueba de chi cuadrado, una prueba no paramétrica, parte, para su análisis, de 
un número mínimo de valores (de frecuencias) y cada grupo reúne este requisito. De esta manera, como se observa en la tabla 6, la prueba de chi cuadrado resultó significativa con los tres grupos; es decir, que hay una asociación entre el factor edad y los usos etimológicos de los pronombres de acusativo. No obstante, al igual que con el factor sexo, se nota una tendencia en relación con las formas emergentes: a mayor edad, mayores tasas de usos innovadores. En el caso de lo/ los con referentes femeninos, por ejemplo, estos se duplican de un grupo etario menor a otro mayor (de $13.8 \%$ a $35.1 \%$ y de este a $70.4 \%$ ). Esto se refleja en los valores de V de Cramer y en los del coeficiente de contingencia.

El nivel de instrucción fue otro factor social que se analizó. En la siguiente tabla, se muestran los hallazgos en relación con el género del referente y las variantes agrupadas la/las y lo/los:

Tabla 7. Variantes con factores instrucción informantes y género referente

\begin{tabular}{|c|c|c|c|c|}
\hline Nivel de instrucción & Género referente & La/las & Lo/los & $\mathbf{n}$ \\
\hline \multirow{2}{*}{ Nivel básico } & Masculino & $8 \quad \mathbf{2 . 6} \%$ & $97.4 \%$ & 309 \\
\hline & Femenino & $83 \quad 64.3 \%$ & $35.7 \%$ & 129 \\
\hline \multirow{2}{*}{ Nivel medio } & Masculino & $1.7 \%$ & $98.3 \%$ & 173 \\
\hline & Femenino & $10384.4 \%$ & $19 \quad \mathbf{1 5 . 6 \%}$ & 122 \\
\hline \multirow{2}{*}{ Nivel superior } & Masculino & $\begin{array}{|ll|}4 & \mathbf{1 . 7} \% \\
\end{array}$ & $98.3 \%$ & 233 \\
\hline & Femenino & $90 \quad 78.3 \%$ & $21.7 \%$ & 115 \\
\hline \multicolumn{5}{|c|}{$\begin{array}{l}\mathrm{N}=1081 \text {. Chi cuadrado. Nivel básico: } 210.8 \mathrm{p}=.000 \text {; nivel medio: } 21 \\
\text { Nivel básico. V de Cramer: } 694 \text { Coeficiente de contingencia: } .570 \text {. } \\
\text { Nivel medio: V de Cramer: } .849 \text { Coeficiente de contingencia: } .647 \text {. } \\
\text { Nivel superior: V de Cramer: .811 Coeficiente de contingencia: } .630\end{array}$} \\
\hline
\end{tabular}

Debido a las altas frecuencias de formas etimológicas, la prueba de chi cuadrado arroja un valor de p significativo (.000) para todos los grupos, lo cual evidencia la asociación de la variable nivel de instrucción con los usos estándares de los pronombres. En relación con las formas innovadoras, se observa que el nivel básico presenta una producción mayor de lo/los con referentes femeninos que el resto de los grupos, lo cual era esperado. Sin embargo, y de manera interesante, el nivel superior tiene un porcentaje mayor que el nivel medio, aunque las diferencias no son significativas.

Nuestro último factor social es la escala de bilingüismo. En la tabla 8, se muestra cómo la producción de las formas pronominales innovadoras incrementa de incipientes a consecutivos y de estos a los simétricos. 
Tabla 8. Variantes con factores escala de bilingüismo y género del referente

\begin{tabular}{|c|c|c|c|c|}
\hline Escala bilingüismo & Género referente & \multicolumn{3}{|c|}{ Variantes } \\
\hline & & $\mathrm{La} / \mathrm{las}$ & Lo/los & $\mathrm{n}$ \\
\hline \multirow{2}{*}{$\begin{array}{c}\text { Monolingües } \\
\text { español }\end{array}$} & Masculino & $6 \quad \mathbf{2 . 9} \%$ & $20197.1 \%$ & 207 \\
\hline & Femenino & $11889.4 \%$ & $14 \quad 10.6 \%$ & 132 \\
\hline \multirow{2}{*}{ Incipientes } & Masculino & $53 \%$ & $16297 \%$ & 167 \\
\hline & Femenino & $5879.5 \%$ & $1520.5 \%$ & 73 \\
\hline \multirow{2}{*}{ Consecutivos } & Masculino & $2 \quad 1.2 \%$ & $16198.8 \%$ & 163 \\
\hline & Femenino & $49 \quad \mathbf{6 3 . 6 \%}$ & $2836.4 \%$ & 77 \\
\hline \multirow{2}{*}{ Simétricos } & Masculino & $2 \quad 1.1 \%$ & $176 \quad 98.9 \%$ & 178 \\
\hline & Femenino & $51 \quad 60.7 \%$ & $33 \quad 39.3 \%$ & 84 \\
\hline \multicolumn{5}{|c|}{$\begin{array}{l}\mathrm{N}=1081 \\
\text { Chi cuadrado. Monolingües: } 259.9 . \mathrm{p}=.000 \text {; incipientes: } 153.3 \mathrm{p}=.000 \text {; } \\
\text { consecutivos: } 121.7 \mathrm{p}=.000 ; \text { simétricos: } 125.5 \mathrm{p}=.000 \\
\text { Monolingües: V de Cramer: .876 Coeficiente de contingencia: .659. } \\
\text { Incipientes: V de Cramer: .799 Coeficiente de contingencia: .624. } \\
\text { Consecutivos: V de Cramer: .712 Coeficiente de contingencia: .580. } \\
\text { Simétricos: V de Cramer: .692 Coeficiente de contingencia: .569 }\end{array}$} \\
\hline
\end{tabular}

De manera similar con los otros factores sociales, la prueba de chi cuadrado resultó significativa dadas las altas tasas de incidencia de las formas etimológicas; es decir, que se evidencia la dependencia que guardan todos los grupos con la variable género del referente y los usos pronominales. Ahora bien, en el uso de lo/los con referentes femeninos, se observa claramente una tendencia a producir más formas innovadoras conforme se avanza en la escala de monolingüismo-bilingüismo. Para comenzar, los monolingües se apartan de las formas estándares y producen un $10.6 \%$; seguidos de los bilingües incipientes, quienes doblan la producción de los primeros con un 20.5\%. Los consecutivos y simétricos muestran tasas muy similares, aunque, inesperadamente, los primeros usaron un poco menos: $36.4 \%$ frente a un $39.6 \%$.

Hasta aquí hemos analizado los usos del sistema pronominal de acusativo en esta comunidad de habla en función del género del referente. En resumen, las tasas abrumadoras de los usos de las formas etimológicas (casi un 90\%), $\mathrm{y}$, en consecuencia, los limitados números de las formas innovadoras nos llevan a comprobar la independencia de las variables sociales: sexo, edad, nivel de instrucción y bilingüismo con estas formas emergentes en las pruebas estadísticas. Con todo, se evidencian tendencias en estos grupos factoriales: las mujeres, los adultos mayores, los participantes con nivel de instrucción básico, y los bilingües simétricos y consecutivos son los innovadores en estos usos emergentes, sobre todo con lo/los con referentes femeninos. Antes de discutir estos resultados a la luz de los estudios previos y de las perspectivas teóricas de este estudio, analicemos lo que ocurre en relación con el rasgo de número. 


\subsection{El sistema pronominal en función del número del referente}

En esta sección, presentamos los resultados de las pruebas de chi cuadrada de la variable número del referente en relación con las variables sociales. En primer lugar, revisemos lo que pasa con la variable sexo:

Tabla 9. Variantes con factores sexo y número referente

\begin{tabular}{|c|c|cc|cc|cc|cc|c|}
\hline Sexo & Número referente & & \multicolumn{1}{c}{ La } & \multicolumn{2}{|c|}{ Lo } & \multicolumn{2}{c|}{ Las } & \multicolumn{2}{c|}{ Los } & n \\
\hline \multirow{2}{*}{ Hombres } & Singular & 77 & $32.2 \%$ & 139 & $58.2 \%$ & 3 & $1.3 \%$ & 20 & $\mathbf{8 . 4 \%}$ & 239 \\
\cline { 2 - 11 } & Plural & 3 & $2.6 \%$ & $\mathbf{8}$ & $\mathbf{7 \%}$ & 23 & $20 \%$ & 81 & $70.4 \%$ & 115 \\
\hline \multirow{2}{*}{ Mujeres } & Singular & 109 & $22.6 \%$ & 355 & $73.5 \%$ & 5 & $1 \%$ & 13 & $\mathbf{2 . 7 \%}$ & 483 \\
\cline { 2 - 11 } & Plural & 9 & $3.7 \%$ & $\mathbf{3 4}$ & $\mathbf{1 3 . 9 \%}$ & 61 & $25 \%$ & 140 & $57.4 \%$ & 244 \\
\hline
\end{tabular}

$\mathrm{N}=1081$.

Chi cuadarado hombres: $221.1 \mathrm{p}=.000$. Mujeres: $476.4 \mathrm{p}=.000$

Hombres: V de cramer: .790 Coeficiente de contingencia: 620

Mujeres. V de cramer: .810 Coeficiente de contingencia: .629

De igual modo que ocurrió con el rasgo de género y la variable sexo, la prueba resulta significativa para la asociación de las variables con las formas etimológicas y, por ende, con las concordancias de número. Aun así, se observa, en los porcentajes de lo con referente plural, una tendencia de las mujeres a producir más que los hombres; en cambio, estos muestran más los con referente singular. Por consiguiente, no es posible identificar un solo grupo como el innovador o principal difusor.

En la siguiente tabla, tenemos los resultados con la variable edad:

Tabla 10. Variantes con factores edad informantes y número referente

\begin{tabular}{|c|c|c|c|c|c|c|c|}
\hline Edad & $\begin{array}{l}\text { Número } \\
\text { referente }\end{array}$ & $\mathbf{L a} /$ & Lo & & Las & Los & $\mathbf{n}$ \\
\hline \multirow{2}{*}{$\begin{array}{l}\text { Grupo A } \\
(18-25)\end{array}$} & Singular & $129 \quad 33.2 \%$ & $231 \quad 59.4 \%$ & & $1.3 \%$ & $23 \mathbf{5 . 9} \%$ & 389 \\
\hline & Plural & $6 \quad 2.6 \%$ & $21 \quad 9.1 \%$ & 59 & $25.7 \%$ & $144 \quad 62.6 \%$ & 230 \\
\hline \multirow{2}{*}{$\begin{array}{l}\text { Grupo B } \\
(26-50)\end{array}$} & Singular & $52 \quad 19.2 \%$ & $208 \quad 76.8 \%$ & 3 & $1.1 \%$ & $8 \quad \mathbf{3} \%$ & 271 \\
\hline & Plural & $5 \quad 4.7 \%$ & $16 \quad \mathbf{1 5} \%$ & & $19.6 \%$ & $65 \quad 60.7 \%$ & 107 \\
\hline \multirow{2}{*}{$\begin{array}{l}\text { Grupo C } \\
(+50)\end{array}$} & Singular & $5 \quad 8.1 \%$ & $55 \quad 88.7 \%$ & 0 & $0 \%$ & $2 \quad 3.2 \%$ & 62 \\
\hline & Plural & $14.5 \%$ & $5 \quad 22.7 \%$ & 4 & $18.2 \%$ & $12 \quad 54.5 \%$ & 22 \\
\hline \multicolumn{8}{|c|}{$\begin{array}{l}\mathrm{N}=1081 \\
\text { Chi cuadrado Grupo A: } 407.3 \mathrm{p}=.000 . \text { Grupo B: } 234.2 \text {; Grupo } \\
\text { Grupo A: V de Cramer: } .811 \text { Coeficiente de contingencia: } .630 . \\
\text { Grupo B: V de Cramer: } .787 \text { Coeficiente de contingencia: } .619 \text {. } \\
\text { Grupo C: V de Cramer: } .749 \text { Coeficiente de contingencia: } .599\end{array}$} \\
\hline
\end{tabular}


Las pruebas muestran que hay asociación del rasgo de número con la variable politómica edad, en tanto que la mayoría de las formas son estándares y estas son concordantes en número. Sin embargo, nótese la tendencia de producir más formas innovadoras con $l o$ con referentes plurales conforme se avanza en edad: el aumento es de un 5\% aproximadamente de un grupo a otro. Los jóvenes producen un $13 \%$ menos de formas innovadoras que los adultos mayores. Cosa contraria ocurre con los con referentes singulares, pues son los jóvenes los que ligeramente recurren más a estos usos que los otros grupos, que se comportan de manera similar.

A continuación, en la siguiente tabla, se observa que la prueba no paramétrica de chi cuadrado resultó significativa con respecto a la relación entre la variable número y la variable social nivel de instrucción con las variantes pronominales, pues son evidentes los porcentajes mayoritarios para las concordancias (el sistema etimológico).

Tabla 11. Variantes con factores instrucción y número referente

\begin{tabular}{|c|c|c|c|c|c|c|c|c|}
\hline $\begin{array}{c}\text { Nivel de } \\
\text { instrucción }\end{array}$ & $\begin{array}{l}\text { Número } \\
\text { referente }\end{array}$ & & La & Lo & Las & & Los & $\mathbf{n}$ \\
\hline \multirow{2}{*}{ Nivel básico } & Singular & \multicolumn{2}{|c|}{$54 / 17.8 \%$} & $23677.9 \%$ & $5 \quad 1.7 \%$ & 8 & $2.6 \%$ & 303 \\
\hline & Plural & 7 & $5.2 \%$ & $2115.6 \%$ & $25 \quad 18.5 \%$ & 82 & $60.7 \%$ & 135 \\
\hline \multirow{2}{*}{ Nivel medio } & Singular & 67 & $37.9 \%$ & $104 \quad 58.8 \%$ & $0 \quad 0 \%$ & 5 & $2.8 \%$ & 177 \\
\hline & Plural & 3 & $2.5 \%$ & $8 \quad 6.8 \%$ & $29.7 \%$ & 72 & $61 \%$ & 118 \\
\hline \multirow{2}{*}{ Nivel superior } & Singular & & $26.9 \%$ & $15463.6 \%$ & $31.2 \%$ & 20 & $8.3 \%$ & 242 \\
\hline & Plural & 2 & $1.9 \%$ & $13 \quad 12.3 \%$ & $24 \quad 22.6 \%$ & 67 & $63.2 \%$ & 106 \\
\hline \multicolumn{9}{|l|}{$\mathrm{N}=1081$} \\
\hline \multicolumn{9}{|c|}{$\begin{array}{l}\text { Chi cuadrado Nivel básico A: } 264.7 \mathrm{p}=.000 \text {. Nivel medio: } 232.6 \text {; Nivel superior } 196.9 \mathrm{p}=.000 \\
\text { Nivel básico: V de Cramer: .777. Coeficiente de contingencia: } 614 \text {. } \\
\text { Nivel medio: V de Cramer: } .888 \text {. Coeficiente de contingencia: } 664 \text {. } \\
\text { Nivel superior: V de Cramer: .757. Coeficiente de contingencia: .601. }\end{array}$} \\
\hline
\end{tabular}

No obstante, se observa de manera interesante que los usos pronominales emergentes no parecen seguir una tendencia organizada jerárquicamente de manera clara y contundente con todas las variantes. En relación con lo plural, por ejemplo, los informantes de nivel medio producen menos formas innovadoras que el grupo del nivel superior. En contraste, con la plural, sí se evidencia esta tendencia: a más bajo nivel de instrucción, mayor número de formas emergentes, y lo mismo pasa con los singular, que nos muestra un resultado inesperado: a mayor nivel de instrucción, mayor número de frecuencias. 
Veamos, enseguida, la función de la escala mono-bilingüismo y su relación con el número del referente y los pronombres átonos de acusativo.

Tabla 12. Variantes con factores escala de bilingüismo y género del referente

\begin{tabular}{|c|c|c|c|c|c|c|}
\hline \multirow[t]{2}{*}{ Escala bilingüismo } & \multirow[t]{2}{*}{ Número referente } & \multicolumn{5}{|c|}{ Variantes } \\
\hline & & $\mathrm{La}$ & Lo & Las & Los & $\mathrm{n}$ \\
\hline \multirow{2}{*}{ Monolingües español } & Singular & $7737.6 \%$ & $10752.2 \%$ & $1.5 \%$ & $178.3 \%$ & 205 \\
\hline & Plural & $5 \quad 3.7 \%$ & $96.7 \%$ & $28.4 \%$ & $82 \quad 61.2 \%$ & 134 \\
\hline \multirow{2}{*}{ Incipientes } & Singular & $47 \quad 25.7 \%$ & $126 \quad 68.9 \%$ & $31.6 \%$ & $7 \quad 3.8 \%$ & 183 \\
\hline & Plural & $0 \quad \mathbf{0} \%$ & $35.3 \%$ & $13 \quad 22.8 \%$ & $41 \quad 71.9 \%$ & 57 \\
\hline \multirow{2}{*}{ Consecutivos } & Singular & $28 \quad 17.1 \%$ & $13381.1 \%$ & $0 \%$ & $3 \quad 1.8 \%$ & 164 \\
\hline & Plural & $5 \quad 6.6 \%$ & $2127.6 \%$ & $23.7 \%$ & $32 \quad 42.1 \%$ & 76 \\
\hline \multirow{2}{*}{ Simétricos } & Singular & $3420 \%$ & $12875.3 \%$ & $21.2 \%$ & $63.5 \%$ & 170 \\
\hline & Plural & $2.2 \%$ & $9 \quad 9.8 \%$ & $15 \quad 16.3 \%$ & $66 \quad 71.7 \%$ & 92 \\
\hline \multicolumn{7}{|c|}{$\begin{array}{l}\mathrm{N}=1081 \text {. Chi cuadrado Incipientes } 177.3 \mathrm{p}=.000 \text {. Consecutivos: } 123.9 \text {; sir } \\
\text { Monolingües: } 214.08 \text {. } \\
\text { Nivel Incipientes : V de Cramer: .860. Coeficiente de contingencia: .652. } \\
\text { Nivel Consecutivos: V de Cramer: .719. Coeficiente de contingencia: .584. } \\
\text { Nivel simétricos: V de Cramer: .840. Coeficiente de contingencia: .643. } \\
\text { Nivel Monolingües: V de Cramer: .795. Coeficiente de contingencia: .622 }\end{array}$} \\
\hline
\end{tabular}

Estadísticamente, la prueba indica que es significativa en tanto que todos los grupos usan abrumadoramente las variantes pronominales siguiendo los patrones del sistema etimológico de acusativo. Aun así, se evidencian dos tendencias: una en la producción de lo con referentes plurales y otra de los con referentes singulares. En la primera, se distingue la producción de menos a más siguiendo una escala de mono-bilingüismo: los monolingües y los incipientes (L1 español y uso incipiente de maya), seguidos de los simétricos (L1 español y maya) y, al final, los consecutivos (L1 maya-L2 español). En la segunda, parece casi un proceso invertido: los monolingües muestran un mayor porcentaje seguido de los incipientes y después de simétricos y consecutivos. Queda claro que el monolingüismo y los diferentes niveles de bilingüismo desempeñan un papel relevante en la producción de estas formas emergentes.

En esta sección, analizamos los usos del sistema pronominal de acusativo en esta comunidad de habla en función del número del referente. En breve, los resultados son muy similares a los relacionado con el género, pues las frecuencias y porcentajes abrumadores de los usos de las formas etimológicas (más de un 90\%) nos llevan a comprobar la independencia de las variables sociales: sexo, edad, nivel de instrucción y bilingüismo con estas formas emergentes en las pruebas estadísticas. No obstante, se muestran tendencias: las mujeres producen más lo con referente plural, pero los hombres evidencian más los con referente singular; es decir, que ambos grupos usan formas emergentes, pues hay más variación en el uso de las variantes innovadoras. 
Con el factor edad, es clara la tendencia a producir más formas emergentes según se avanza en edad: los adultos mayores son los que evidencian una mayor producción de lo con referentes plurales, pero los jóvenes producen más los con referentes singulares. Los participantes con nivel de instrucción básico son los innovadores con lo plural, aunque hay desfases en la jerarquía de nivel de instrucción, ya que los de nivel medio evidencian menos innovación que los de nivel superior, y estos últimos producen más los con referentes singulares que el resto de los grupos. En la escala de mono-bilingüismo, hay también dos tendencias principales: la producción de lo con referentes plurales es liderada por los bilingües consecutivos, mientras que la innovación de los con referentes singulares es liderada por los monolingües. Veamos, a continuación, la función de las variables internas.

\subsection{Las variables internas y su relación con los usos pronominales}

En esta parte, examinamos la posible relación de dependencia entre las variables semánticas, el género y el número y las variantes pronominales. Presentamos primero los resultados del género en relación con las variables semánticas y, seguidamente, en dependencia con el número.

Con respecto al primero, la prueba de chi cuadrado resultó significativa tanto para referentes + humanos como -humanos, dadas las altas tasas de usos etimológicos. No obstante, encontramos una tendencia del rasgo [ \pm humano] del referente, el más prominente en la escala de animacidad, al favorecer la aparición de las formas emergentes lo/los con referentes femeninos cuando el rasgo de estos es [-humano] (ver tabla 12). Analizamos solamente lo/los dado que fueron las variantes innovadoras más frecuentes.

Tabla 13. Variantes con rasgo humano y referentes femeninos

\begin{tabular}{|c|cc|}
\hline Humano & \multicolumn{2}{|c|}{ Lo/los } \\
\hline +Humano & 12 & $16.9 \%$ \\
\hline -Humano & 79 & $26.6 \%$ \\
\hline $\begin{array}{l}\text { N=91. Chi cuadrado +humano: } 169.3 \mathrm{p}=.000 . \\
\text {-humano: .493.5 } \mathrm{p}=.000 .\end{array}$ \\
\hline
\end{tabular}

Algo similar ocurre con el rasgo de animacidad. Estadísticamente, la prueba de chi cuadrado fue significativa, en tanto que tanto animados como inanimados mantienen relación de concordancia gramatical de género. Es decir, que se sigue el padrón del sistema etimológico. No obstante, se observa un porcentaje ligeramente mayor de formas emergentes con referentes femeninos en el caso de inanimados, como se muestra en la tabla 14. 
Tabla 14. Variantes con factores animacidad y referentes femeninos

\begin{tabular}{|c|c|}
\hline Animacidad & Lo/los \\
\hline +Animado & $19.7 \%$ \\
\hline -Animado & $25.9 \%$ \\
\hline \multicolumn{2}{|c|}{$\begin{array}{l}\mathrm{N}=91 . \text { Chi cuadrado animados: } 205.9 \mathrm{p}=.000 \\
\text { Inanimados } 458.1 \mathrm{P}=.000\end{array}$} \\
\hline
\end{tabular}

Por otro lado, la variable semántica especificidad tampoco resultó significativa estadísticamente, pero hay una clara duplicación de formas innovadoras cuando los referentes femeninos no son específicos. La tabla 15 nos ilustra esto.

Tabla 15. Variantes con factores especificidad y referentes femeninos

\begin{tabular}{|c|cc|c|}
\hline Especificidad & \multicolumn{2}{|c|}{ Lo/los } & n \\
\hline +Específico & 77 & $22.9 \%$ & 336 \\
\hline --Específico & 14 & $42.4 \%$ & 33 \\
\hline $\begin{array}{l}\mathrm{N}=91 \text {. Chi cuadrado +específicos: } 623.8 \mathrm{p}=.000 . \\
\text {-Específicos } 37.2 \mathrm{p}=.000\end{array}$ \\
\hline
\end{tabular}

En contraste, con la variable definitud no se observa ni siquiera una tendencia a favorecer estos usos pronominales emergentes, ya que tanto definidos como indefinidos mostraron una tasa de $24.7 \%$ y $24.6 \%$, respectivamente con $l o / l o s$ con referentes femeninos.

Tabla 16. Variantes con factores definitud y referentes femeninos

\begin{tabular}{|c|cc|}
\hline Definitud & \multicolumn{2}{|c|}{ Lo/los } \\
\hline +Definido & 77 & $24.7 \%$ \\
\hline -Definido & $14 \quad 24.6 \%$ \\
\hline $\begin{array}{l}\mathrm{N}=91 . \text { Chi cuadrado +definidos: } 571.3 .8 \mathrm{p}=.000 . \\
\text {-definidos } 90.8 . \mathrm{p}=.000 .\end{array}$ \\
\hline
\end{tabular}

Estas fueron las únicas variables semánticas que mostraron alguna tendencia a favorecer la presencia de las formas pronominales innovadoras. El rasgo de continuidad del referente y los rasgos semánticos del sujeto no resultan significativas ni muestran tendencias.

Atendiendo ahora la relación entre las variables semánticas y el número del referente, y empezando con el rasgo [ \pm humano] del referente, los resultados estadísticos fueron significativos, dado que tanto referentes +humanos como -humanos siguen el patrón del sistema pronominal etimológico. Si bien hay una diferencia porcentual de los -humanos con más lo plurales, esta es mínima. De hecho, los singular decrece con el rasgo -humano, lo cual es inesperado. Veamos esto en la tabla siguiente: 
Tabla 17. Variantes con rasgo humano y número referente

\begin{tabular}{|c|c|c|c|}
\hline Humano & Número referente & Lo & Los \\
\hline \multirow{2}{*}{ + Humano } & Singular & $75 \quad 54.7 \%$ & $107.3 \%$ \\
\hline & Plural & $9 \quad 9.1 \%$ & $8080.8 \%$ \\
\hline \multirow{2}{*}{-Humano } & Singular & $421 \quad 71.6 \%$ & $23 \quad 3.9 \%$ \\
\hline & Plural & $33 \quad 12.5 \%$ & $1434.4 \%$ \\
\hline \multicolumn{4}{|c|}{$\begin{array}{l}\mathrm{N}=1081 . \text { Chi cuadrado +Humano: } 144.4 \mathrm{p}=.000 . \text {-Humano: } 557.4 \mathrm{p}=.000 \\
\text { +Humano: V de cramer: } .782 \text { Coeficiente de contingencia: } .616 \\
\text {-Humano. V de cramer: } .809 \text { Coeficiente de contingencia: } .629\end{array}$} \\
\hline
\end{tabular}

De manera similar se comporta el rasgo animacidad en relación con el número. La tabla 17 nos muestra que lo plural se incrementa con referentes inanimados un $6 \%$, pero, contrariamente, los singular aumenta con referentes animados en un $6 \%$ aproximadamente.

Tabla 18. Variantes con factores animacidad y número referente

\begin{tabular}{|c|c|c|c|}
\hline Animacidad & Número referente & Lo & Los \\
\hline \multirow{2}{*}{+ Animado } & Singular & $88 \quad 57.9 \%$ & $149.2 \%$ \\
\hline & Plural & $128.1 \%$ & $12181.8 \%$ \\
\hline \multirow{2}{*}{-Animado } & Singular & $408 \quad 71.1 \%$ & $193.3 \%$ \\
\hline & Plural & $30 \quad 14 \%$ & $10247.7 \%$ \\
\hline \multicolumn{4}{|c|}{$\begin{array}{l}\mathrm{N}=1081 \\
\text { Chi cuadrado +Animado: } 182.1 \mathrm{p}=.000 . \text {-Animado: } 508.3 \mathrm{p}=.000 \\
\text { +Animado: V de cramer: } .779 \text { Coeficiente de contingencia: } .615 \\
\text {-Animado. V de cramer: } .803 \text { Coeficiente de contingencia: } .626\end{array}$} \\
\hline
\end{tabular}

Con el rasgo definitud, se evidencia un pequeño aumento de lo plural con referentes indefinidos; pero los singular muestra similares tasas independientemente de la valencia del rasgo de definitud. En la tabla 18, podemos observarlo:

Tabla 19 Variantes con factores definitud y número referente

\begin{tabular}{|c|c|c|c|}
\hline Definitud & Número referente & Lo & Los \\
\hline \multirow{2}{*}{ + Definido } & Singular & $68.4 \%$ & $27 \quad 4.6 \%$ \\
\hline & Plural & $11.2 \%$ & $20662.6 \%$ \\
\hline \multirow{2}{*}{-Definido } & Singular & $93 \quad 67.9 \%$ & $64.4 \%$ \\
\hline & Plural & $5 \quad 15.2 \%$ & $1751.5 \%$ \\
\hline \multicolumn{4}{|c|}{$\begin{array}{l}\mathrm{N}=1081 . \text { Chi cuadrado +Definido: } 598.1 \mathrm{p}=.000 . \text {-Definido: } 93.4 \mathrm{p}=.000 \\
\text { +Definido: V de cramer: } .807 \text { Coeficiente de contingencia: } .628 \\
\text {-Definido. V de cramer: } .741 \text { Coeficiente de contingencia: } .596\end{array}$} \\
\hline
\end{tabular}


Los porcentajes de especificidad son muy similares a estos de definitud, por lo que prescindiremos de la tabla. El resto de variables (rasgos semánticos del sujeto) no resultaron significativas para estas formas innovadoras ni muestran tendencias claras.

Con estos hallazgos, tanto de las variables sociales como lingüísticas, podemos constatar que, dados estos datos, en esta comunidad de habla, el uso del sistema etimológico de los pronombres de acusativo predomina con casi un $84 \%$. No se evidencia una total reorganización del sistema pronominal de acusativo, pues las formas innovadoras solo constituyen un $16 \%$ de todos los datos. No obstante, mostramos que estos se comportan similarmente a los de variedades en donde sí se evidencia una reorganización o simplificación del sistema; es decir, se identifican las mismas condiciones o restricciones lingüísticas y sociales en el fenómeno en cuestión. Los resultados de nuestro análisis sugieren que son, precisamente, los objetos prototípicos, entidades [-humanas], [-animadas], [-específicas], [-definidas], los que parecen más sensibles a favorecer las formas emergentes. Este hallazgo coincide con estudios previos de este fenómeno en el español en contacto con una lengua amerindia (Hernández y Palacios, 2015;Avelino, 2017 y Torres, 2018).

No obstante, en relación con el número, se encontraron dos tendencias opuestas, pues, por una parte, tenemos el uso innovador reportado en estudios previos sobre el español en contacto con lenguas amerindias: lo con referentes plurales, el cual mantiene relación de dependencia con entidades [-humanas], [-animadas], [-específicas], [-definidas], igual que en la neutralización del género. Sin embargo, po otra parte, identificamos una nueva tendencia: el uso del pronombre los con referentes singulares, el cual se comporta de manera totalmente opuesta: las entidades con rasgos [+humano], [+animado], [+definido] y [+específico] favorecen la producción de los usos discordantes. Este resultado inesperado no se ha reportado en la literatura previa. Podemos sugerir, a manera de hipótesis, que este los con referentes singulares surge como una forma de ultracorrección entre los informantes. Retomamos esta hipótesis posteriormente.

Con todo esto, constatamos una neutralización de género principalmente $y$, en menor medida, de número, lo que conllevaría, si el fenómeno avanzara y se difundiera en la comunidad, a un sistema simplificado bi- casual, con distinción de caso, esto es el uso de lo y los en una primera fase y de lo en una siguiente para marcar objeto directo, y le para objeto indirecto. Es decir, se encaminaría al uso de estos pronombres como marcas de objeto. Este hallazgo evidencia la tendencia propuesta por Fernández Ordoñez (1999:1341) con respecto a la simplificación del sistema pronominal de acusativo y dativo en situaciones de contacto y coincide con diversos estudios previos de situación de contacto del español con lenguas amerindias (García Tesoro, 2002; Palacios, 2005; Hernández y Palacios, 2015; Avelino, 2017 y Torres, 2018). 
Podemos dar cuenta de estos resultados a partir del sistema pronominal de acusativo de la lengua otomí, de una cuestión de adquisición, y de los múltiples factores lingüísticos y sociales que afectan el fenómeno. Empezando con el primero, como en la sección 2.3 "El sistema pronominal de objeto directo en otomí" propusimos, si los hablantes de la comunidad de habla del presente estudio tuvieran un sistema de complemento directo como el que documenta Palancar (2009), se esperarían omisiones de objeto directo en la producción de los bilingües; pero esto no ocurrió de ninguna manera, como al inicio de la sección de resultados expusimos. Por otra parte, si tuvieran el paradigma propuesto por Hekking y Andrés de Jesús (1987), entonces se esperarían usos más cercanos al sistema etimológico o distinguidor del español mexicano estándar, ya que en esa variedad de otomí tienen pronombres de acusativo que no distinguen género, pero sí número. Y esto fue lo que evidenciamos con estos resultados, precisamente: neutralización de los rasgos de género, principalmente $\mathrm{y}$, en menor medida, de número. De esta manera, podría sugerirse una convergencia estructural del español y del otomí en los hablantes de esta comunidad. No obstante, el reducido número de usos innovadores nos lleva a indagar sobre el papel de otros factores que, indudablemente, están afectando la difusión del fenómeno.

Los estudios de adquisición como lengua materna (L1) o como segunda lengua (L2) también nos pueden arrojar luz para explicar el fenómeno. La jerarquización semántica de rasgos está avalada también en estudios de adquisición del español (Aguado, 2000;, Hernandez Pina, 1990, Pueyo, 1992; Klee, 1989; Calvo, 1996; y Collantine, 1987; referenciados por Palacios, 2005), los cuales evidencian la adquisición en primer lugar de la distinción de caso, seguida de la de número y de género, en la mayoría de los casos (aunque el número puede ser el último en algunos). A partir de los estudios de Domínguez 2003; Ezeizabarrena 1996, 1997 y De la Mora 2004, con niños con impedimento del habla, se observa que la adquisición de los clíticos en español puede consistir en diferentes etapas de desarrollo: primero se adquieren los clíticos de primera y segunda persona y después los de tercera persona. Además, en relación con esto últimos, se observa una primera fase con el uso de lo como pronombre exclusivo para codificar objetos. De ahí que lo sea el pronombre identificado en la mayoría de los estudios previos de español en contacto como el principal innovador.

Hernández (2017) propone, para la adquisición de L1 y L2, que hay una primera etapa en la cual, ante tanto input y material lingüístico (los cuales implican una fuerte actividad mental y diferentes procesos cognitivos para su procesamiento y consiguiente producción), es natural el uso de estrategias que satisfagan la necesidad comunicativa. Estas son, precisamente, la aplicación 
de los universales de Greenberg (1963) en cuanto a las jerarquías semánticas: caso>género> número, y de la teoría de la marcación. Así, van a preferir la distinción de caso, así como las formas no marcadas: masculinas para género; y singular para número en una fase inicial de la adquisición.

El concepto de transparencia semántica también complementa esta explicación. Leufkens (2013) y Hengeveld y Leufkens (2018) hipotetizan que el contacto lingüístico propicia más transparencia en las lenguas implicadas. Así, en situaciones de contacto, se espera una mayor frecuencia de formas transparentes que de opacas, dado el alto grado de inteligibilidad de las primeras $\mathrm{y}$, consecuentemente, se favorecen cambios lingüísticos dirigidos hacia una transparencia más rica. En las categorías de opacidad, tenemos la redundancia (número), y las formas basadas en la forma (concordancias y género gramatical), que en estos datos se neutralizan, pero no en la misma medida: la tendencia es principalmente en género $\mathrm{y}$, seguidamente, en número, aunque se dio el caso excepcional de ultracorrección con los singular. Es decir, se observa una jerarquización de rasgos semánticos, como propone Greenberg y una cuestión de transparencia como los factores guía en esta etapa.

Siguiendo con Hernández (2017), en una sucesiva etapa, se evidencian tendencias divergentes entre los dos grupos (niños y adultos) condicionadas por factores extralingüísticos, principalmente, como son la frecuencia de input (podemos agregar cantidad y calidad), la frecuencia de uso de las formas normativas, la evidencia positiva y la propia madurez del niño. En un contexto monolingüe, se favorecen estos factores de manera tal que los niños adquieren la especificación de los rasgos de género y número, y los integran a su interlengua. No obstante, en el caso de los bilingües (niños y adultos) en contextos de intenso contacto, las condiciones difieren, pues hay una exposición a dos lenguas, pero no en el mismo grado, y la frecuencia de uso de las formas normativas del español y la evidencia positiva pueden diferir significativamente. (Hernández 2017: 179). Otros factores extralingüísticos, como el nivel de instrucción y la presión social, impactan en estas divergencias.

Nuestros hallazgos, precisamente, muestran una estratificación social relacionada con el fenómeno en cuestión: los adultos mayores, las mujeres, los miembros del nivel educativo básico y los bilingües consecutivos son los que producen más formas innovadoras, hecho que coincide con los más recientes estudios de contacto del español con lenguas amerindias en México, los cuales han integrado variables sociales y una escala de bilingüismo (Véase Hernández y Palacios 2015; Avelino 2017; y Torres 2018). En términos de la sociolingüística variacionista, estas variables lingüísticas pronominales se comportan como marcadores lingüísticos, pues se asocian con cambios inconscientes que adquieren un valor social; muestran estratificación social y estilística (aunque esto último no lo integramos en el análisis) y actitudes negativas por parte de los hablantes (Labov 2001: 196). 
Indudablemente, las actitudes lingüísticas desempeñan una función relevante en el cambio lingüístico y las situaciones de desplazamiento. Ya en la perspectiva teórica, hacíamos explícita referencia a las actitudes negativas identificadas en la comunidad (Hekking 2002; Avelino 2017; Tavarez 2019), las cuales, muchas veces, se originan en los grupos monolingües de español. Estas generan vergüenza a la comunidad otomí hacia su propia lengua y ejercen tal presión social que lleva al desplazamiento lingüístico, situación en la coinciden tanto Hekking (2002) como Avelino (2017) en sus estudios en comunidades otomíes.

En atención a estos antecedentes, y retomando nuestro segundo objetivo: analizar la función del contacto en estos procesos, las pregunta para contestar son ¿Qué función desempeña el contacto en este fenómeno pronominal? ¿Estamos ante una situación de cambio inducido por contacto? Para responderlas, primero debemos determinar si estamos ante una situación de variación solamente o ante un cambio lingüístico, efectivamente. En los estudios sociolingüísticos, los cambios en progreso o en marcha muestran porcentajes de ocurrencia (más del 15\%) y mantienen correlación con las variables sociales. En este estudio, reportamos un $16 \%$ de formas emergentes y mostramos tendencias de dependencia con las variables extralingüísticas. Adicionalmente, se ha identificado que los cambios "desde abajo" (aumento de la naturalidad lingüística) son promovidos por las clases más bajas y, en este estudio, es claro que los informantes con nivel de instrucción más bajo condicionan favorablemente la innovación.

No obstante, no podemos concluir con que se trata de un cambio en progreso porque, si recurrimos al concepto de estudio en tiempo aparente para estudiar el cambio lingüístico (Shen 1990; Labov 1994, 2001), se esperaría que el grupo más joven tuviera una producción mayor de innovaciones que la de los otros grupos etarios y, con estos resultados, ocurre lo contrario. Es decir, si los jóvenes favorecieran el fenómeno, este avanzaría y se impondría con el tiempo, pero, con estos datos, son los adultos mayores los que lo favorecen.

Estos hallazgos pueden sugerir un cambio abortado o en retroceso, dado el decremento de formas innovadoras documentadas aquí en relación con investigaciones previas del español en contacto con otomí (Lizárraga 2014; Avelino 2017), al menor uso por parte de los jóvenes, y a la presencia de los con referentes singulares, que podemos interpretar como un fenómeno de ultracorrección. Son, precisamente, los más jóvenes, los hombres, los de mayor nivel educativo y los monolingües los que producen más los con referentes singulares. Es decir, son los agentes innovadores opuestos a los que neutralizan género y número. Este último dato sugiere que la comunidad de habla ha adquirido cierta consciencia lingüística del fenómeno y responden a este (quizás ya se haya alcanzado el carácter de estereotipo) pluralizando el pronombre incluso con referentes singulares. Este fenómeno, indudablemente, previene el progreso de las formas neutralizadas motivadas por diversas causas. 
Si se trata, entonces, de un cambio en retracción, asumimos que hubo un cambio inicial (neutralización de los rasgos de género y de número en las formas pronominales) y este, como pudimos evidenciar arriba, está fuertemente condicionado por variables internas y variables externas. Entre estas últimas, el contacto lingüístico desempeña un papel fundamental. Palacios $(2011,25)$ propone que el cambio indirecto inducido por contacto consiste en cambios multicausales compatibles con las tendencias internas del sistema en los que el contacto funciona como un acelerador del cambio.

Para determinar la función del contacto, resulta metodológicamente útil incluir hablantes de los diferentes grupos de una escala de bilingüismo. De esta manera, se evidencia una producción diferenciada del fenómeno por parte de los hablantes y podemos identificar los líderes del cambio. En este estudio, identificamos así a los propagadores del cambio: en primer lugar, los bilingües consecutivos seguidos por los simétricos, los incipientes $\mathrm{y}$, finalmente, los monolingües. Interesante resultó que este último grupo también mostrara ocurrencias de la variación en el uso de los pronombres y esto puede deberse al contacto que mantienen con la comunidad bilingüe.

Thomason (2010, 36-7) destaca que los cambios lingüísticos son multicausales y aduce a factores sociales y lingüísticos como condicionantes de los cambios inducidos por contacto. En los primeros, incluye la presencia vs. la ausencia de un aprendizaje imperfecto, la intensidad del contacto y las actitudes de los hablantes. Más que un aprendizaje imperfecto, proponemos, como arriba lo hicimos, que se trata del uso de estrategias requeridas para satisfacer necesidades comunicativas inmediatas, las cuales están mediadas por factores lingüísticos, cognitivos, culturales y sociales., como Palacios Alcaine $(2017,8)$ enfatiza.

Definitivamente, la intensidad del contacto y las actitudes de los hablantes determinan estos cambios inducidos por contacto. Arriba discutimos la situación de desplazamiento de esta comunidad. Las causas de dicha situación pueden ser múltiples, y las consecuencias también: una reducción en la población bilingüe, un menor contacto de lenguas y un decremento en el nivel de bilingüismo en la comunidad de habla. Para los cambios inducidos por contacto, el contacto lingüístico es necesario, pero no es suficiente, como enfatiza Thomason (2010); debe haber un contacto intenso. Así, este requisito parece no cumplirlo la comunidad aquí estudiada para difundir y hacer extensivo el fenómeno.

Con respecto a las actitudes, también ya discutimos anteriormente que estas son negativas, tanto de los hablantes otomíes como de los monolingües de español, lo que provoca el desplazamiento de la lengua originaria y un acercamiento de la comunidad de habla a las formas estándares en español, que ven como prestigiosas (de ahí el $84 \%$ de formas estándares). El fenómeno de ultracorrección aquí identificado muestra el grado de conciencia lingüística 
de la comunidad de habla y evidencia las actitudes negativas hacia las formas innovadoras provenientes de los grupos bilingües y de instrucción básica.

Sin duda, como propone Thomason, los cambios son multicausales y, con seguridad, hay una interacción de variables que impactan y determinan los cambios. Por ejemplo, en México, la población indígena conforma únicamente $1 \%$ del total de estudiantes en nivel superior (Chávez Arellano, 2008). De ahí que el bilingüismo en México se relaciona con clases sociales bajas y bajos niveles educativos.

\section{A manera de conclusión}

Este estudio tuvo como objetivos determinar las condiciones internas y externas que motivan la variación y posible cambio en el sistema pronominal átono en el español en contacto con otomí en la comunidad de Santiago Mexquititlán en México, así como analizar la función del contacto en esta variación o cambio. Los resultados muestran que el sistema pronominal átono de tercera persona de acusativo de esta comunidad de habla es muy similar al sistema etimológico, pues solo se registró un $16 \%$ de formas pronominales innovadoras; los objetos nulos y casos de leísmo fueron escasos.

Si bien la tasa de formas emergentes es baja, mostramos un subsistema que evidencia una tendencia similar a la que constatamos en otras variedades de español en situación de contacto lingüístico intenso: las formas pronominales átonas de acusativo tienden a no especificar los rasgos de género y número. También, mostramos que las condiciones lingüísticas y extralingüísticas resultan similares, pues son las entidades -humanas, -animadas, -definidas y -específicas las que favorecen la presencia de estos usos emergentes; son también las mujeres, los informantes de nivel básico, la gente adulta mayor y los bilingües consecutivos los líderes de esta innovación.

Argumentamos que el proceso de gramaticalización de las formas pronominales, que se desarrolla desde el español antiguo, es multicausal y que se explica, con estos datos, a partir de las características de la lengua de contacto, el otomí en este caso; las estrategias de comunicación urgentes en la situación de contacto, las cuales se fundamentan en la transparencia semántica y la jerarquías de rasgos semánticos, las características del input lingüístico, las presiones sociales, las actitudes y el grado de contacto lingüístico.

Mostramos, en relación con este subsistema, un cambio que parece en retracción o retroceso dadas las condiciones de un decremento en las formas emergentes reportadas en estudios previos con esta misma variedad (aunque en diferente comunidad), la poca producción de estos usos innovadores por parte del grupo etario más joven, así como el incipiente fenómeno de ultracorrección identificado con el uso de los con referentes singulares. 
Finalmente, encontramos que el contacto lingüístico desempeña una función fundamental en la variación y cambios aquí analizados, ya que no solo actúa como un acelerador del cambio, que posibilita la reorganización y recategorización del sistema pronominal átono de tercera persona, como se ha señalado en estudios previos, sino también como un factor que desencadena o dispara el cambio. Es decir, el mismo contacto de lenguas convierte el contexto en "tierra fértil" para que los hablantes bilingües recurran a estrategias comunicativas sustentadas en principios lingüísticos "naturales": transparencia semántica, jerarquización de rasgos semánticos, y en motivaciones cognitivas y pragmáticas, que derivan en variación inicialmente. Si el contacto es intenso y no hay presión social hacia los usos normativos, la difusión se extenderá rápidamente hacia todos los grupos en la escala de bilingüismo, incluidos también los monolingües. Si bien determinamos un cambio en retroceso, este tuvo su origen y desarrollo en el contacto de lenguas. Es decir, se trata de un cambio inducido por el contacto lingüístico y todas las condiciones lingüísticas y extralingüísticas que este conlleva.

Se hace impostergable investigar con rigurosidad y de manera sistemática los factores extralingüísticos que parecen interactuar y tener un impacto considerable en los fenómenos lingüísticos en situación de contacto.

\section{Referencias}

Avelino Sierra, Rosnátaly. 2017. Contacto Lingüístico entre el español y el otomí en San Andrés Cuexcontitlán. Tesis de licenciatura, Universidad Nacional Autónoma de México.

Calvo Pérez, Julio. 1996-1997 "Pronominalización en español andino: ley de mínimos e influencia del quechua y del aimara”. Anuario de Lingüística Hispánica. Homenaje al Dr. Germán de Granda 12-13: 521-543.

Chávez Arellano, María Eugenia. 2008. "Ser indígena en la educación superior ¿desventajas reales o asignadas?”, Revista de la Educación Superior 37, n. 148:3155.

Fernandéz Ordoñez, Inés. 1999. "leísmo, laísmo y loísmo" En Gramática descriptiva de la lengua española. Volumen 1: Sintaxis básica de las clases de palabras, dirs., Ignacio Bosque y Violeta Demonte, p. 1317-1397. Madrid: Espasa Calpe.

Flores Cervantes, Marcela. 2006. "leísmo, laísmo y loísmo" En Sintaxis histórica de la lengua española, dir., Concepción Company Company, p. 669-749. México: Universidad Nacional Autónoma de México-Fondo de Cultura Económica.

Flores Farfán, José Antonio. 1999. Cuatreros somos y toindioma hablamos: Contactos y conflictos entre el náhuatl y el español en el sur de México. México, D.F.: CIESAS.

Tesoro García, Ana Isabel. 2010. “Español En Contacto Con El Tzutujil En Guatemala: Cambios En El Sistema Pronominal átono De Tercera Persona." Revista Internacional De Lingüistica Iberoamericana 8, n. 1:133-56. 
Godenzzi, Juan. 1986. Pronombres De Objeto Directo E Indirecto Del Castellano En Puno. Lexis 10, n. 2:187-201. http://revistas.pucp.edu.pe/index.php/lexis/article/ view/8358.

Granda, Germán. 1996. "Origen y mantenimiento de un rasgo (o dos) del español andino. La omisión de los clíticos preverbales”. Lexis 20:275-298.

Granda, Germán. 2001. Estudios de lingüística andina. Lima: PUCP.

Guerrero Galván, Alonso. 2006. "Hablamo(s) así todo(s) igual(es): concordancia plural en un contexto bilingüe”. En Líderes lingüísticos, ed., Pedro Martín Butragueño, p. 89-110. México: El Colegio de México.

Guerrero Galván, Alonso. 2009. "Otho ?bui. Migrantes otomíes en la ciudad de México”. Lengua y Migración 1:39-56.

Guerrero Galván, Alonso y San Giacomo Trinidad, Marcela. 2014. "E1 llamado español indígena en el contexto del bilingüismo". En Historia Sociolingüistica de México, dirs., Rebeca Barriga Villanueva y Pedro Martín Butragueño, p. 1459-1526. México: El Colegio de México.

Guillán, María Isabel. 2012. Procesos de cambio lingüístico inducido por contacto en el español del Nea: el sistema pronominal átono. Tesis doctoral, Universidad Autónoma de Madrid.

Hekking, Ewald. 2001. "Cambios gramaticales por el contacto entre el otomí y el español”. En Lo propio y lo ajeno en las lenguas austronésicas y amerindias: procesos interculturales en el contacto de lenguas indígenas con el español en el Pacifico e Hispanoamérica, eds., Thomas Stolz y Klaus Zimmermann, p. 127-151. Madrid-Frankfurt: Iberoamericana-Vervuert.

Hekking, Ewald. 2002. "Desplazamiento, pérdida y perspectivas para la revitalización del Hñañho". Estudio de cultura otopame 3: 221-248.

Hekking, Ewald y Andrés de Jesús, Severiano. 1984. Gramática otomí. México: Universidad Autónoma de Querétaro.

Hernández, Edith, y Azucena Palacios. 2015. "El Sistema Pronominal átono En La Variedad De español En Contacto Con Maya Yucateco". Círculo De Lingüística Aplicada a La Comunicación 61: 36-78. https://doi.org/10.5209/rev_CLAC.2015. v61.48467.

INALI (Instituto Nacional de Lenguas Indígenas). 2015. Proyecto de indicadores sociolingüísticos de las lenguas indígenas nacionales. (Octubre 10, 2018), Gobierno de México. Recuperado de: https://site.inali.gob.mx/Micrositios/estadistica_basica/ estadisticas2015/pdf/general/ general7.pdf

INEGI (Instituto Nacional de Estadística y Geografía). 2010. Consultado el 11 de mayo de 2014 en Intercultural a través de la Acción-desde-Abajo, Amsterdam: Universiteit van Amsterdam.

Klee, Carol A. 1990. Spanish-Quechua language contact: The clitic pronoun system in Andean Spanish, WORD 41, n. 1:35-46. 
Klee, Carol y Caravedo, Rocio. 2005. Contact-Induced Language Change in Lima, Peru: The Case of Clitic Pronouns. En Selected Proceedings of the 7th Hispanic Linguistics Symposium, ed. David Eddington, 12-21. Estados Unidos: Cascadilla Proceeding Project.

Lastra, Yolanda. 1987. "El español de una familia bilingüe otomí”. En Studia Humanitatis. Homenaje a Rubén Bonifaz Nuño, p. 239-244. México: Universidad Nacional Autónoma de México.

Lastra, Yolanda. 1992. El otomí de Toluca. México: Universidad Nacional Autónoma de México.

Lizárraga, Glenda. 2014. "Los pronombres clíticos del español en hablantes bilingües español-otomí”. Estudios de Lingüística Aplicada 59:554-584.

Martínez, Angelita.1996. "Lenguas y culturas en contacto. Uso de clíticos lo-la-le en la región del Noreste argentino”. Signo y Seña 6:139-177.

Martínez, Angelita. 2000. Estrategias etnopragmáticas en el uso de los pronombres clíticos lo, la y le, en la Argentina, en zonas de contacto con lenguas aborígenes. Leiden: University of Leiden Press.

Martínez, Angelita. 2001. "Cuando "nada” es algo: la relación sintáctico-pragmática en el contacto de lenguas". En Homenaje a Ofelia Kovacci, comps., Angela di Tullio y Elvira N. de Arnoux, p. 345-358. Buenos Aires: Eudeba.

Martínez, Angelita. 2006. El español de la Argentina en contacto con lenguas indígenas: estrategias etnopragmáticas. Tópicos del Seminario 15:97-110.

Mendieta, Eva. y Molina, Isabel. 1995. Juicios de gramaticalidad ante una estructura morfosintáctica del español hablado en el País Vasco. Mundaiz 50:25-35.

Moya, Ofelia. 2006. Los pronombres átonos en el castellano andino: Un estudio del habla de La Paz. Bolivia: Carrera de Lingüística e Idiomas de la Universidad Mayor de San Andrés

Olate, Aldo, Wittig, Fernando y Hasler, Felipe. 2014. Análisis tipológico-funcional de un rasgo del español de contacto mapuche/castellano. Onomázein 30:169-189.

Palacios, Azucena. 1998. Variación sintáctica en el sistema pronominal del español paraguayo. Anuario de Lingüística Hispánica 14:451-474.

Palacios, Azucena. 2000. El sistema pronominal del español Paraguayo: un caso de contacto de lenguas. En Teoría y práctica del contacto: el español de América en el candelero, ed., Julio Calvo Pérez, p. 122-143. Madrid-Frankfurt: Iberoamericana Vervuert.

Palacios, Azucena. 2005. Aspectos teóricos y metodológicos del contacto de lenguas: el sistema pronominal del español en áreas de contacto con lenguas amerindias. En El español en América: aspectos teóricos, particularidades, contactos, eds. Volker Noll y Klaus Zimmermann, p. 63-94. Madrid-Frankfurt: Iberoamericana-Vervuert.

Palacios, Azucena. 2006. Cambios inducidos por contacto en el español de la sierra ecuatoriana: la simplificación de los sistemas pronominales (procesos de neutralización y elisión). Tópicos del Seminario 15:197-230. 
Palacios, Azucena. 2015. "El Sistema Pronominal átono De 3a Persona: Variedades De español En Contacto Con Otras Lenguas". Círculo De Lingüística Aplicada a La Comunicación, p. 61:3-9. https://doi.org/10.5209/rev_CLAC.2015.v61.48465.

Palacios, Azucena. 2017. Introducción. Sobre los cambios lingüísticos en situaciones de contacto. En Variación y cambio lingüístico en situaciones de contacto, coord., Azucena Palacios, p. 7-20. Madrid-Frankfurt: Iberoamericana-Vervuert.

Palancar, Enrique. 2009. Gramática y textos del hñoñho. Otomí de San Idelfonso Tultepec, Querétaro. Volumen I: Gramática. México: Universidad Autónoma de Querétaro.

Paredes, Liliana y Valdez, María Luz. 2008. "Language Contact and Change: Direct Object Leísmo in Andean-Spanish". En Selected Proceedings of the 4th Workshop on Spanish Sociolinguistics, eds. Maurice Westmoreland y Juan Antonio Thomas, p. 140-148. Somerville, MA: Cascadilla Proceedings Project.

Pfänder, Stefan. 2009. Gramática mestiza. Con referencia al castellano de Cochabamba. La Paz: Instituto boliviano de lexicografía y otros estudios.

Tavarez, Gerardo. 2019. "Santiago Mexquititlán, mezcla de cultura y tradición”. Diario de Querétaro, 9 de Agosto de 2019. https://www.diariodequeretaro.com.mx/local/ santiago-mexquititlan-mezcla-de-cultura-y-tradicion-4013425.html

Thomason, Sarah. 2008. "Social and Linguistic Factors as Predictors of ContactInduced Change", Journal of Language Contact 2, n.1:42-56, doi: https://doi. org/10.1163/000000008792525381

Thomason, Sarah. 2010. "Contact Explanations in Linguistics. En The Handbook of Language Contact, ed., Raymond Hickey, p. 31-47. Chichester, West Sussex: Wiley-Blackwell.

Torres Sánchez, Nadiezdha. 2015. "El Sistema Pronominal En El español De bilingües Tepehuano Del Sureste-español”. Círculo De Lingüística Aplicada a La Comunicación 61: 10-35. https://doi.org/10.5209/rev_CLAC.2015.v61.48466.

Torres Sánchez, Nadiezdha. "Simplificación del sistema pronominal átono del español de bilingües tepehuano del sureste y español". En Estudios de variación geolinguística, coords., Leonor Orozco y Alonso Guerrero Galván, p. 517-550. México: INAH. 